University of Louisville

ThinkIR: The University of Louisville's Institutional Repository

$8-2013$

\title{
Validation of an RPE-based submaximal oxygen consumption test using a total body recumbent stepper for individuals with spinal cord injury : a proof of concept study.
}

John Patrick McCulloch

University of Louisville

Follow this and additional works at: https://ir.library.louisville.edu/etd

\section{Recommended Citation}

McCulloch, John Patrick, "Validation of an RPE-based submaximal oxygen consumption test using a total body recumbent stepper for individuals with spinal cord injury : a proof of concept study." (2013).

Electronic Theses and Dissertations. Paper 942.

https://doi.org/10.18297/etd/942

This Master's Thesis is brought to you for free and open access by ThinkIR: The University of Louisville's Institutional Repository. It has been accepted for inclusion in Electronic Theses and Dissertations by an authorized administrator of ThinkIR: The University of Louisville's Institutional Repository. This title appears here courtesy of the author, who has retained all other copyrights. For more information, please contact thinkir@louisville.edu. 


\title{
VALIDATION OF AN RPE-BASED SUBMAXIMAL OXYGEN CONSUMPTION TEST USING A TOTAL BODY RECUMBENT STEPPER FOR INDIVIDUALS WITH SPINAL CORD INJURY: A PROOF OF CONCEPT STUDY
}

\author{
By \\ John Patrick McCulloch \\ B.S., University of Dayton, 2011

\begin{abstract}
A Thesis
Submitted to the Faculty of the College of Education and Human Development of the University of Louisville in Partial Fulfillment of the Requirements for the Degree of
\end{abstract}

Master of Science

Department of Exercise Physiology

University of Louisville

Louisville, Kentucky

August 2013 



\section{VALIDATION OF AN RPE-BASED SUBMAXIMAL OXYGEN CONSUMPTION TEST USING A TOTAL BODY RECUMBENT STEPPER FOR INDIVIDUALS WITH SPINAL CORD INJURY: A PROOF OF CONCEPT STUDY}

\section{By}

John Patrick McCulloch

B.S., University of Dayton, 2011

A Thesis Approved on

May 29, 2013

By the following Thesis Committee:

Daniela Terson de Paleville, PhD., Thesis Advisor

Ann Swank, PhD.

Douglas Lorenz, PhD.

Saori Hanaki-Martin, $\mathrm{PhD}$. 


\section{DEDICATION}

This thesis is dedicated to my parents

Mr. J. Stephen McCulloch

and

Mrs. Patricia J. McCulloch

who have always believed in me and have blessed me with so much. 


\section{ACKNOWLEDGEMENTS}

I would like to thank my thesis advisor, Dr. Daniela Terson de Paleville, for her guidance, patience, and encouragement. I would also like to thank Dr. Ann Swank and Dr. Saori Hanaki-Martin for their comments and assistance. I wish to extend a huge thank you to Dr. Doug Lorenz for helping me with the statistics- without his help this would not have been possible. Finally, many thanks to my friends and family, without your support I would have been a mess. 


\begin{abstract}
VALIDATION OF AN RPE-BASED SUBMAXIMAL OXYGEN CONSUMPTION TEST USING A TOTAL BODY RECUMBENT STEPPER FOR INDIVIDUALS WITH SPINAL CORD INJURY: A PROOF OF CONCEPT STUDY

John P. McCulloch
\end{abstract}

May 29, 2013

Exercise training is crucial to improve cardiovascular health and quality of life in people with spinal cord injuries (SCI). A key limitation is the lack the validated tests to evaluate cardiovascular fitness in this population. The purpose of this study was to validate a submaximal test to predict maximal oxygen consumption in individuals with SCI. Ten able-bodied subjects and two individuals with SCI completed an RPE-based submaximal oxygen consumption test and a graded maximal oxygen consumption test on a NuStep T4 stepper. The results indicate that prediction of $\mathrm{VO}_{2}$ max from an RPE-based protocol is feasible and can produce reliable predicted $\mathrm{VO}_{2}$ max values in the able bodied population. This study is a proof of concept to the implementation of a submaximal test protocol using a total body recumbent stepper to predict $\mathrm{VO}_{2}$ max in able-bodied individuals. Additionally, this study shows evidence of feasibility of performing this test in SCI individuals. 


\section{TABLE OF CONTENTS}

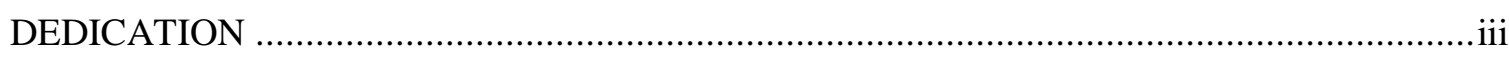

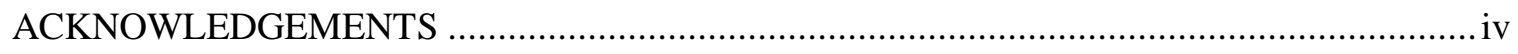

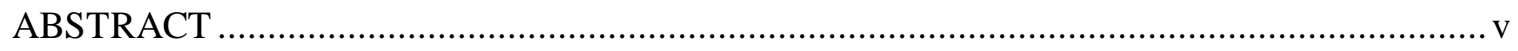

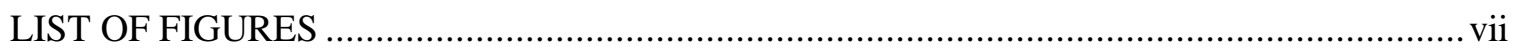

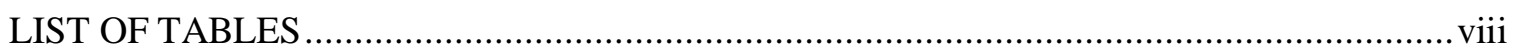

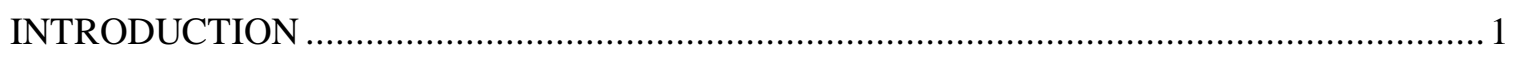

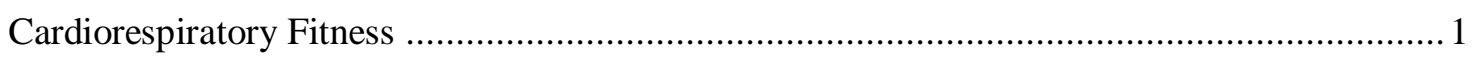

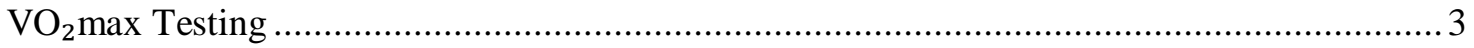

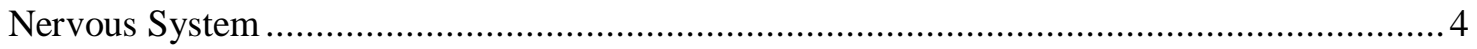

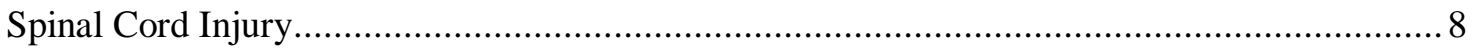

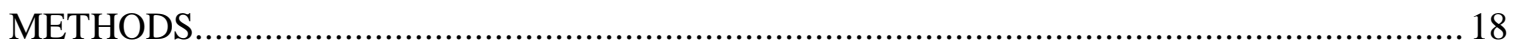

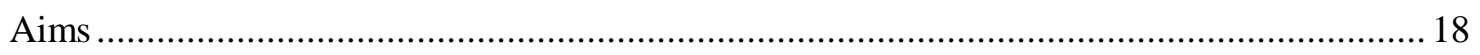

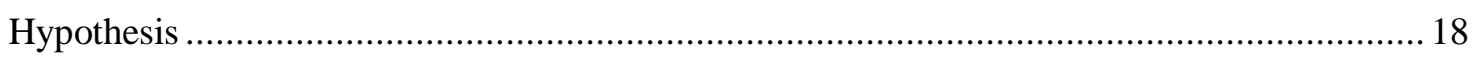

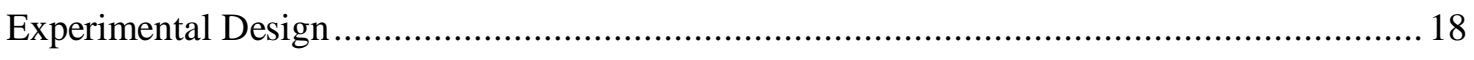

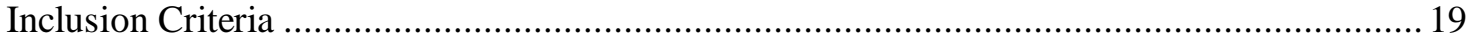

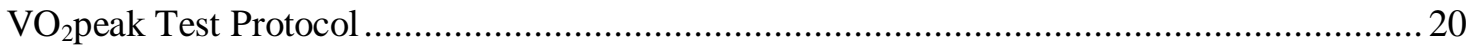

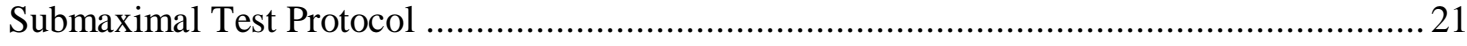

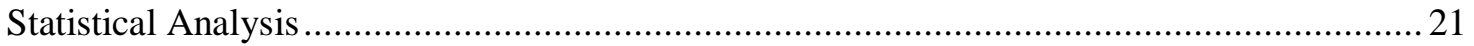

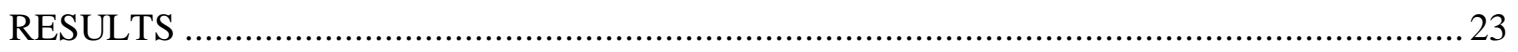

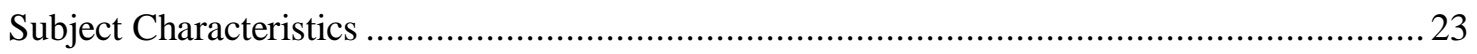

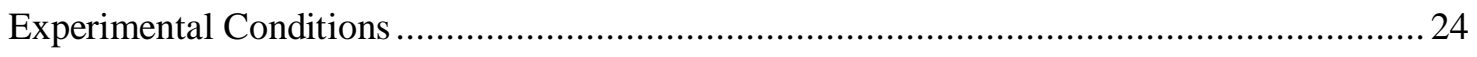

Mixed Effects Model Building - Technical Considerations ............................................ 24

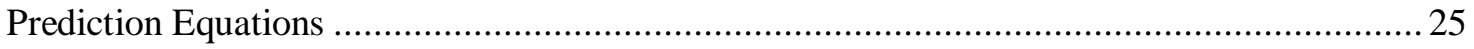

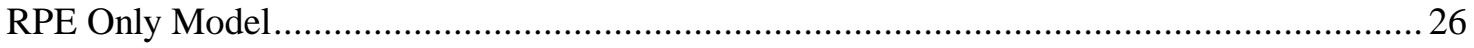

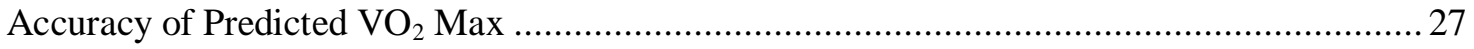

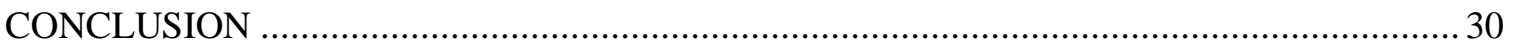

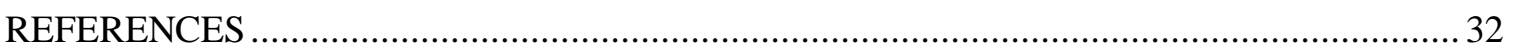

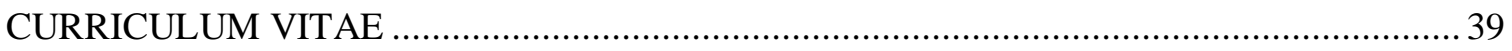




\section{LIST OF FIGURES}

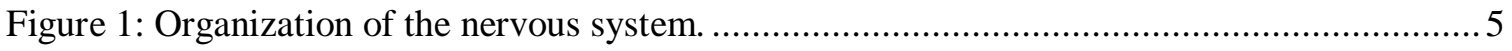

Figure 2: Cross-sectional view of the spinal cord. (VanPutte, Seeley, Regan, \& Russo, 2011)..... 7

Figure 3: International Standards Worksheet (page 1). (S. C. Kirshblum et al., 2011) ................ 11

Figure 4: International Standards Worksheet (page 2). (S. C. Kirshblum et al., 2011) ................ 11

Figure 5: Schematic illustration of the major organs and areas innervated by the sympathetic and parasympathetic nervous system according to spinal cord level. Taken from

asialearningcenter.org. .....

Figure 6: Representative T1-weighted images from the upper thigh of (A) able-bodied (AB) female, (B) female with spinal cord injury (SCI) and low muscle fat, (C) male with SCI and high muscle fat, and (D) diabetic male with SCI and high intramuscular fat. (McCully et al., 2011) .. 14 Figure 7: Observed $\mathrm{VO}_{2}$ from the submaximal exercise test (solid lines with dots) and maximal exercise test (dashed lines) tests. Marked X's indicate $\mathrm{VO}_{2}$ max predicted from the submaximal data.

Figure 8: Observed vs. Predicted $\mathrm{VO}_{2}$ max. Bars from points represent $95 \%$ confidence intervals of prediction. Observations for which confidence interval bars cross the dashed line are those for which the observed maximum $\mathrm{VO}_{2}$ was contained in the $95 \%$ confidence. 


\section{LIST OF TABLES}

Table 1: Life expectancy for post injury by severity and age at injury. Taken from Spinal Cord Injury Facts and Figures at a Glance. (National Spinal Cord Injury Statistic Center, 2012).......... 9

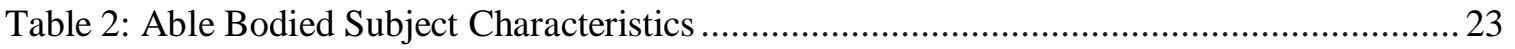

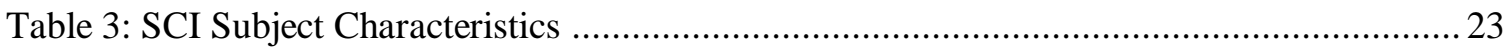

Table 4: $\mathrm{VO}_{2}$, watts, and heart rate values recorded and correlating RPE during subject N89's submaximal and maximal exercise tests

Table 5: $\mathrm{VO}_{2}$, and watt values recorded and correlating RPE during subject C28's submaximal and maximal exercise tests

Table 6: Estimates of fixed effects terms based on watts and RPE with 95\% confidence intervals

Table 7: Estimates of fixed effects based on RPE only with $95 \%$ confidence intervals ............... 26

Table 8: Observed and predicted $\mathrm{VO}_{2}$ from RPE 9-17, 9-15, and 9-13................................. 28 


\section{INTRODUCTION}

\section{Cardiorespiratory Fitness}

Cardiorespiratory fitness, which is a functional state of the respiratory, cardiovascular, and skeletal muscle systems, is necessary for an individual's ability to perform moderate-to-high intensity exercise for prolonged periods of time (Caspersen, Powell, \& Christenson, 1985; Pescatello, 2013). Low levels of cardiorespiratory fitness have been associated with an increased risk of premature death from all causes while an increase in cardiorespiratory fitness is associated with a decline in morbidity and mortality(Blair et al., 1995; Kodama et al., 2009; Paffenbarger Jr et al., 1993). High levels of cardiorespiratory fitness are associated with higher habitual levels of activity, and are associated with many health benefits (Haskell et al., 2007; Pate et al., 1995; Pescatello, 2013). Cardiovascular responses to physical activity depend on the type and intensity of the physical activity of the individual. Dynamic exercises that use large muscles groups will result in a larger response from the cardiovascular system than other types of exercise (Brooks, Fahey, \& Baldwin, 2007).

Cardiorespiratory fitness of an individual is assessed by measuring their oxygen consumption $\left(\mathrm{VO}_{2}\right)$ levels at a maximal level of work $\left(\mathrm{VO}_{2} \mathrm{max}\right)$ (Bruce, Kusumi, \& Hosmer, 1973; Pescatello, 2013; Pollack, Schmidt, \& Jackson, 1980; Shephard et al., 1968). The rate at which an individual consumes oxygen increases as the intensity of the activity increases. Higher $\mathrm{VO}_{2}$ max values indicate an individual is more fit, as their bodies are more efficient at consuming oxygen. The rate of oxygen transportation to 
tissues, the capacity of the blood to carry oxygen, and the amount of oxygen taken from the blood all affect $\mathrm{VO}_{2}$ and can be expressed in the following equation (Brooks et al., 2007):

$$
\dot{V} O_{2}=\dot{Q}(a-v)_{\mathrm{O}_{2}}
$$

$\dot{Q}$ represents cardiac output, which is the amount of blood pumped by the left ventricle of the heart per minute. The two determinants of cardiac output are heart rate, which is the frequency of contractions of the heart per minute, and stroke volume, the amount of blood ejected from the heart during a single cardiac contraction. Cardiac output is expressed in liters/minute. Arteriovenous oxygen difference, expressed as $(a-v)_{\mathrm{O}_{2}}$, is the difference in oxygen content between the veins and arteries, essentially measuring how much oxygen was taken up by the tissues. This variable is expressed in milliliters of oxygen per $100 \mathrm{~mL}$ of blood or volumes percent (vol \%) (Brooks et al., 2007).

Cardiac output and arteriovenous oxygen difference each account for about $50 \%$ of the increase in oxygen consumption during submaximal exercise (Brooks et al., 2007). As the intensity of exercise increases and approaches maximal levels, cardiac output plays an increasingly more important role in oxygen consumption, mainly due to an increasing heart rate. As the intensity of an exercise increases, oxygen uptake by active skeletal muscle also increases proportionally. This increase is mostly due to higher cardiac output. Endurance trained individuals show higher efficiency in both the uptake of oxygen by the tissues and cardiac output due to an increased stroke volume each time the heart contracts. Therefore, a more physically fit athlete will have a lower $\mathrm{VO}_{2}$ at a 
specific power output or intensity than an untrained individual exercising at the same power output or intensity (Brooks et al., 2007).

\section{$\mathrm{VO}_{2}$ max Testing}

Direct measurement of $\mathrm{VO}_{2} \max$ is typically done using open circuit spirometry. In this procedure, an individual breathes through a low pressure valve that sends their expired air to a mixing chamber where the fractions of carbon dioxide, oxygen, and ventilation are analyzed by a pneumotachometer. Even with automated gas analysis, attention to detail during calibration is essential in order to obtain accurate results (Pescatello, 2013).

A maximal exercise test using open-circuit spirometry is considered to be the most accurate way to measure $\mathrm{VO}_{2}$ max since it directly measures the expired gas of a subject at a maximal workload (Noonan \& Dean, 2000; Pescatello, 2013). However, maximal testing is not always possible or the best option for health professionals. Costs related to buying the equipment, paying technicians to run the equipment, and the space needed to run the test all restrict the ability to perform maximal tests to a mainly laboratory setting. Another issue with direct measurement maximal tests is that it requires the subject to exercise to volitional fatigue. This may require medical supervision and emergency equipment during the test. Often it is not worth the risk to put already at-risk subjects through a maximal test. Additionally, many patients do not want to exercise at high intensities. Measuring $\mathrm{VO}_{2}$ max with a maximal test, while accurate, may not be possible or safe for certain populations and situations.

For those situations when maximal testing is not possible or desirable, prediction of $\mathrm{VO}_{2}$ max through the use of submaximal tests is possible (Noonan \& Dean, 2000; 
Pescatello, 2013). A wide variety of submaximal tests have been validated by examining the relationship between directly measured $\mathrm{VO}_{2}$ max and predicted $\mathrm{VO}_{2}$ max from physiologic responses at a specific work rate or between directly measured $\mathrm{VO}_{2}$ max and test performance (Al-Rahamneh \& Eston, 2011a, 2011b; Figoni, 2010; Hol, Eng, Miller, Sproule, \& Krassioukov, 2007; Pescatello, 2013). The most common method of predicting $\mathrm{VO}_{2} \max$ is with heart rate at specific workloads. While not as accurate in assessing an individual's cardiovascular fitness, submaximal exercise tests are often preferred. Submaximal tests typically do not require expensive analysis equipment, they can be conducted outside of a laboratory setting, and are usually safer as the subject is not exercising to exhaustion.

\section{Nervous System}

The nervous system is a complex and vital network made up of the brain, spinal cord, nerves, and sensory receptors that coordinates the actions of all other body systems to maintain homeostasis with constantly changing stimuli (Cohen \& Memmler, 2013; Wilmore, Costill, \& Kenney, 2008). The nervous system maintains homeostasis in the body by constantly receiving sensory input both internally and externally, processing that information, and initiating and controlling a motor response (Cohen \& Memmler, 2013; Jenkins, Kemnitz, \& Tortora, 2007; Powers \& Howley, 2009; Wilmore et al., 2008). The nervous system is composed of two parts: the central nervous system, made up of the brain and spinal cord, and peripheral nervous system, which includes all neurons outside the central nervous system (Cohen \& Memmler, 2013; Jenkins et al., 2007; Powers \& Howley, 2009; Wilmore et al., 2008). 
The peripheral nervous system can be further divided according to function: the sensory (afferent) division, which sends sensory information to the central nervous system; and the motor (efferent) division, which carries out the actions dictated by the central nervous system (Powers \& Howley, 2009; Wilmore et al., 2008). The motor division can then be further divided into the autonomic and somatic nervous systems (Cohen \& Memmler, 2013; Jenkins et al., 2007; Powers \& Howley, 2009; Wilmore et al., 2008). The somatic nervous system innervates skeletal muscle and can be voluntarily controlled (Cohen \& Memmler, 2013; Jenkins et al., 2007; Powers \& Howley, 2009; Wilmore et al., 2008). The autonomic nervous system innervates smooth muscle, cardiac muscle, and some glands (Cohen \& Memmler, 2013; Jenkins et al., 2007; Powers \& Howley, 2009). The heart, blood vessels, respiratory tract, and sweat glands are also under autonomic control (Jenkins et al., 2007; Krassioukov et al., 2012). The autonomic nervous system can be even further divided into sympathetic, parasympathetic, and enteric divisions (Jenkins et al., 2007; Wilmore et al., 2008). Effectors are typically innervated by both sympathetic and parasympathetic divisions and control opposing actions (Jenkins et al., 2007). The sympathetic division will prepare a body for activity while the parasympathetic division governs the body at rest (Jenkins et al., 2007).

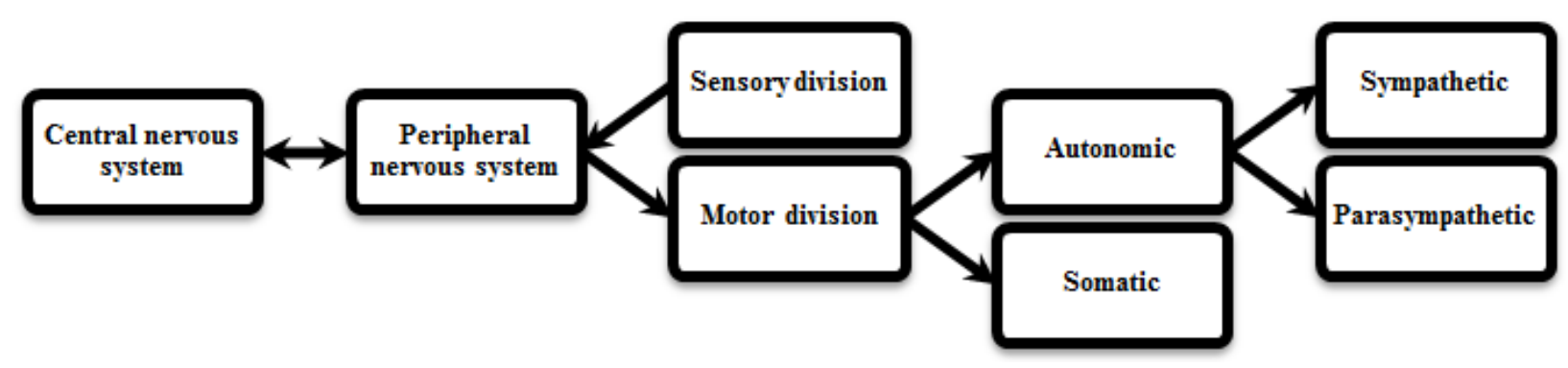

Figure 1: Organization of the nervous system. 
Sensory and motor impulses going to and from the brain must travel through the spinal cord (Cohen \& Memmler, 2013; S. C. Kirshblum et al., 2011). Protected by the vertebrae, the spinal cord extends from the foramen magnum to the second lumbar vertebra and has four segments: cervical, thoracic, lumbar, and sacral (Cohen \& Memmler, 2013; Jenkins et al., 2007). The spinal cord consists of gray matter, which is shaped like a butterfly, and white matter, which surrounds the gray matter. Gray matter is made up of the cell bodies of neurons, unmyelinated axons, dendrites, and neuroglia, receiving and integrating information coming to and from the spinal cord. White matter consists of myelinated axons and neurons and serves as the major pathway for the propagation of sensory and motor information to and from the brain, respectively (Jenkins et al., 2007; S. C. Kirshblum et al., 2011).

The gray matter is further subdivided into the anterior horns, posterior horns, and lateral horns (Jenkins et al., 2007). The cell bodies of somatic motor neurons are found in the anterior horns, providing nerve impulses for the skeletal muscles. The posterior horns receive input from sensory receptors, as they contain somatic and autonomic sensory neuron cell bodies. The lateral horns are only found in the thoracic, upper lumbar, and sacral segments of the spinal cord and contain cell bodies of autonomic motor neurons which regulate the activity of smooth muscle, cardiac muscle, and glands (Jenkins et al., 2007).

White matter is similarly divided into regions. The anterior and posterior horns of the gray matter divide the white matter into three columns: anterior, lateral, and posterior. These columns contain tracts that contain bundles of axons that either come from the same area, or are carrying similar information (Jenkins et al., 2007). Tracts that contain 
axons bringing sensory information to the brain are called ascending tracts. The tracts carrying motor impulses down the spinal cord and away from the brain are called descending tracts (Jenkins et al., 2007).

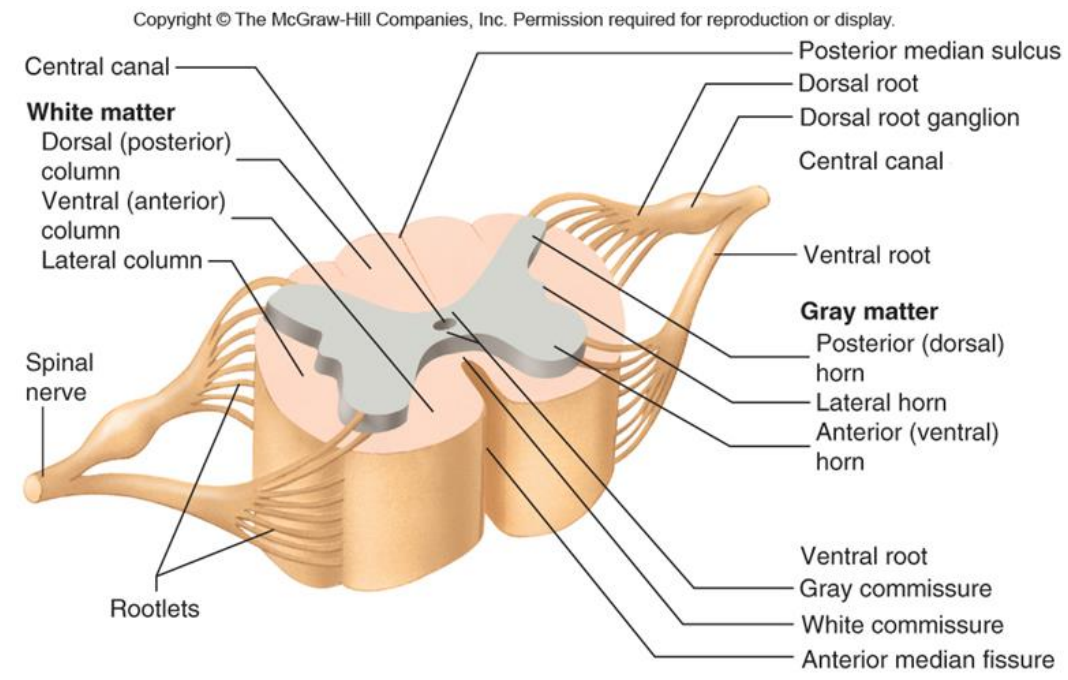

(a) Anterolateral view

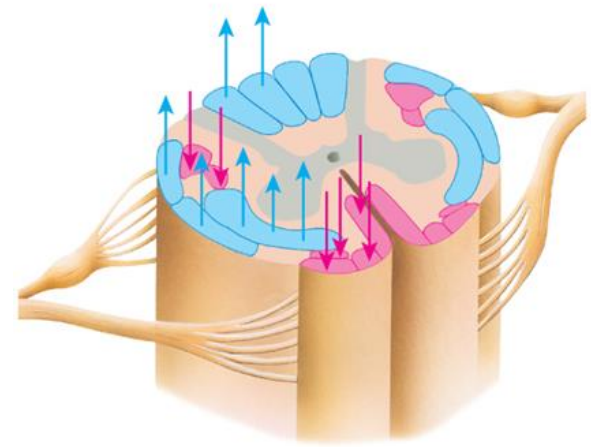

Ascending nerve tracts

Descending nerve tracts

(c) Anterolateral view

Figure 2: Cross-sectional view of the spinal cord. (VanPutte, Seeley, Regan, \& Russo, 2011)

Thirty-one pairs of spinal nerves branch from the spinal cord and are numbered according to the level at which they arise from the spinal cord (Cohen \& Memmler, 2013). Two structures called roots attach each spinal nerve to the spinal cord. The dorsal root contains sensory axons, with the cell bodies of sensory neurons stored in the dorsal root ganglion (Cohen \& Memmler, 2013; Jenkins et al., 2007). The ventral root is made up of motor neurons, with the cell bodies of these neurons stored in the anterior horns. 
Each spinal nerve is named according to where it rises from the spinal cord (Cohen \& Memmler, 2013; Jenkins et al., 2007). The nerves that arise from the inferior part of the spinal cord continue to travel down the vertebral column together until they each exit at a specific intervertebral foramen. This segment is called the cauda equina, meaning "horse's tail" due to its similarity in appearance (Cohen \& Memmler, 2013; Jenkins et al., 2007).

\section{Spinal Cord Injury}

Spinal cord injury (SCI) is a lesion of the spinal cord and affects the conduction of sensory and motor signals across the site of the lesion (Figoni, 2010; Waring et al., 2010). This leads to a variety of dysfunctions of motor, sensory, and autonomic control (Figoni, 2010; Theisen, 2012; West, Mills, \& Krassioukov, 2012). It is estimated there are approximately 12,000 new SCI cases each year in the United States (National Spinal Cord Injury Statistic Center, 2012). The total number of people living with an SCI is estimated to be 265,000 individuals. SCI affects young adults more than any other age group, however the median age of incident has risen from 28.7 years old from 1973-1979 to 40.7 years of age in 2005 (National Spinal Cord Injury Statistic Center, 2012). Males are overwhelmingly more at risk than females, with $80.7 \%$ of spinal cord injuries reported to the national database. Motor vehicle accidents account for $40.4 \%$ of all spinal cord injuries, with the second most common being falls. The life expectancy of individuals with SCI has risen and will continue to increase, but they still have a shorter life expectancy than their able-bodied counterparts. The first year after the injury has a much higher mortality rate than during the subsequent years (National Spinal Cord Injury Statistic Center, 2012). Pneumonia and other respiratory illnesses are the most common 
cause of death in the first year and thereafter (Brown, DiMarco, Hoit, \& Garshick, 2006;

Garshick et al., 2005). Reasons for a higher rate of mortality after SCI include level of lesion and completeness of injury, older age at injury, and injury in earlier calendar years (Brown et al., 2006; Garshick et al., 2005).

\begin{tabular}{|c|c|c|c|c|c|c|c|c|c|c|c|}
\hline & \multicolumn{10}{|c|}{ Life expectancy (years) for post-injury by severity of injury and age at injury } \\
\hline & & \multicolumn{5}{|c|}{ For persons who survive the first 24 hours } & \multicolumn{5}{|c|}{ For persons surviving at least 1 year post-injury } \\
\hline $\begin{array}{c}\text { Age } \\
\text { at } \\
\text { Injury }\end{array}$ & No SCI & $\begin{array}{c}\text { Motor } \\
\text { Functional at } \\
\text { Any Level }\end{array}$ & Para & $\begin{array}{c}\text { Low } \\
\text { Tetra } \\
\text { (C5-C8) }\end{array}$ & $\begin{array}{c}\text { High } \\
\text { Tetra } \\
\text { (C1-C4) }\end{array}$ & $\begin{array}{l}\text { Ventilator } \\
\text { Dependent- } \\
\text { Any Level }\end{array}$ & $\begin{array}{c}\text { Motor } \\
\text { Functional at } \\
\text { Any Level }\end{array}$ & Para & $\begin{array}{c}\text { Low } \\
\text { Tetra } \\
\text { (C5-C8) }\end{array}$ & $\begin{array}{c}\text { High } \\
\text { Tetra } \\
\text { (C1-C4) }\end{array}$ & $\begin{array}{l}\text { Ventilator } \\
\text { Dependent- } \\
\text { Any Level }\end{array}$ \\
\hline 20 & 58.6 & 52.6 & 45.2 & 40.0 & 35.7 & 17.1 & 53.0 & 45.8 & 41.0 & 37.4 & 23.8 \\
\hline 40 & 39.4 & 34.1 & 27.6 & 23.3 & 19.9 & 7.3 & 34.5 & 28.2 & 24.2 & 21.2 & 11.4 \\
\hline 60 & 22.4 & 17.7 & 12.8 & 9.9 & 7.7 & 1.5 & 18.0 & 13.2 & 10.4 & 8.6 & 3.2 \\
\hline
\end{tabular}

Table 1: Life expectancy for post injury by severity and age at injury. Taken from Spinal Cord Injury Facts and Figures at a Glance. (National Spinal Cord Injury Statistic Center, 2012)

Lesion level and amount of damage to the spinal cord in the transverse plane play a large part in determining the consequences and severity of an SCI. The most obvious of these consequences is paralysis of the muscles that are innervated below the level of lesion. In complete spinal cord injuries, neuronal communication to and from the brain will be completely halted. Voluntary motor control below the lesion level may be lost, while a loss of inhibition from upper control centers may give rise to reflex contractions and muscle spasticity. Sensory information like muscle length, joint position, pain, temperature, and pressure may also be halted due to this interruption of the neural pathway. Testing the affected muscles and skin sensitivity can accurately determine the completeness of the injury as well as level of lesion (S. C. Kirshblum et al., 2011; Marino, 2007; Waring et al., 2010)

The International Standards for Neurological Classification of Spinal Cord Injury (ISNCSCI) with the ASIA Impairment Scale (AIS) is the most commonly used and accepted method for determining the severity and level of a lesion (S. C. Kirshblum et al., 
2011; Marino, 2007; Waring et al., 2010; West et al., 2012). In this assessment, the patient undergoes a series of tests examining their sensory and motor function. The sensory test consists of light touch and pin pricks on both the left and right sides of the body for the different dermatomes. The motor preservation evaluation examines different myotomes (for example, elbow flexors are innervated by C5). Using the scores from the sensory and motor tests, the single neurological level of the injury can be determined by finding the most rostral of the sensory and motor levels.

The ASIA scale rates the severity on an A to E system (S. C. Kirshblum et al., 2011; Waring et al., 2010). A grade of "A" is considered "complete"; the patient has no sensory or motor function below the sacral segments S4-S5. "B" is called "sensory complete", the patient has sensory function, but no motor function below the lesion level and includes the sacral segments S4-S5. "C" is "motor incomplete" where motor function is preserved below the neurological level, and more than half the muscles below the level of injury have a muscle grade below 3. "D" is also considered "motor incomplete", however at least half of key muscle functions below the level of the lesion have a muscle grade equal to or greater than 3. "E" is considered "normal", if a patient who has had prior deficits undergoes the INSCSCI testing and is graded normal, they receive this score. Non-SCI patients will not receive an AIS grade. 


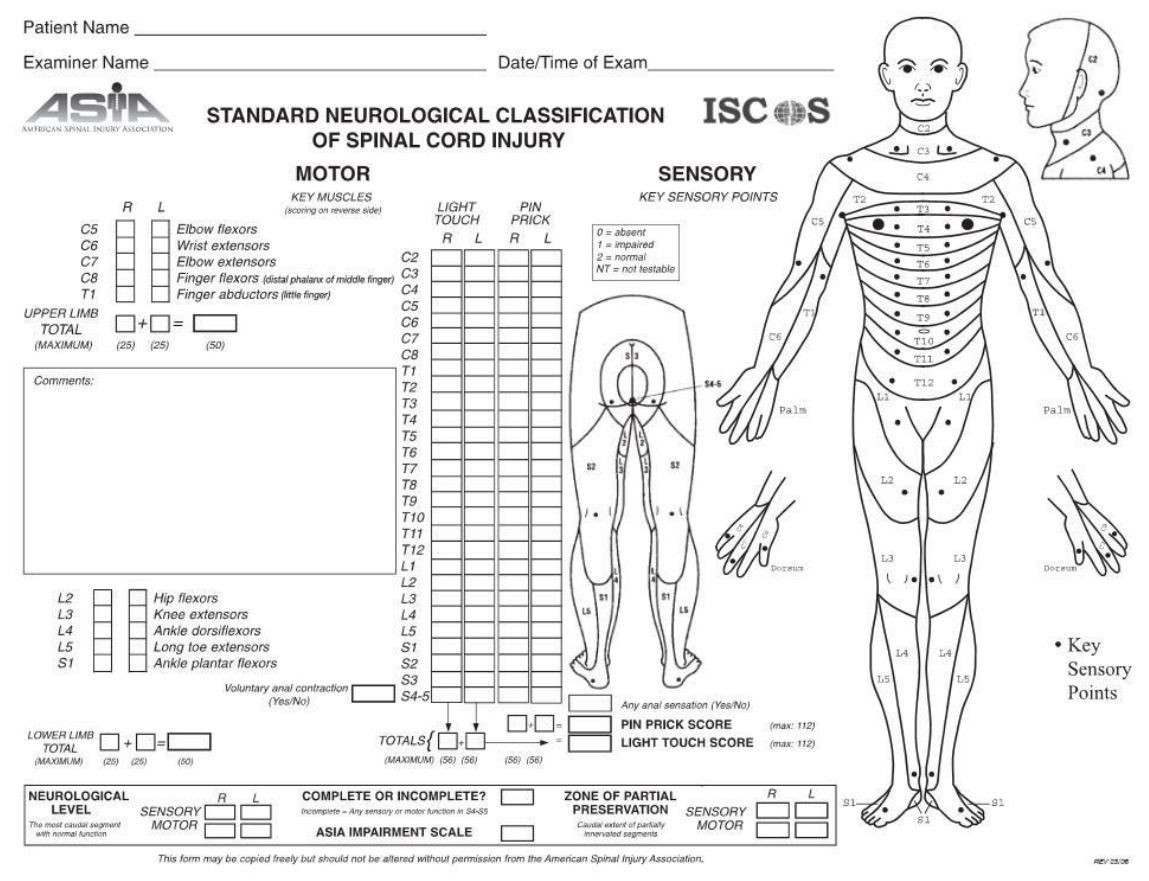

Figure 3: International Standards Worksheet (page 1). (S. C. Kirshblum et al., 2011)
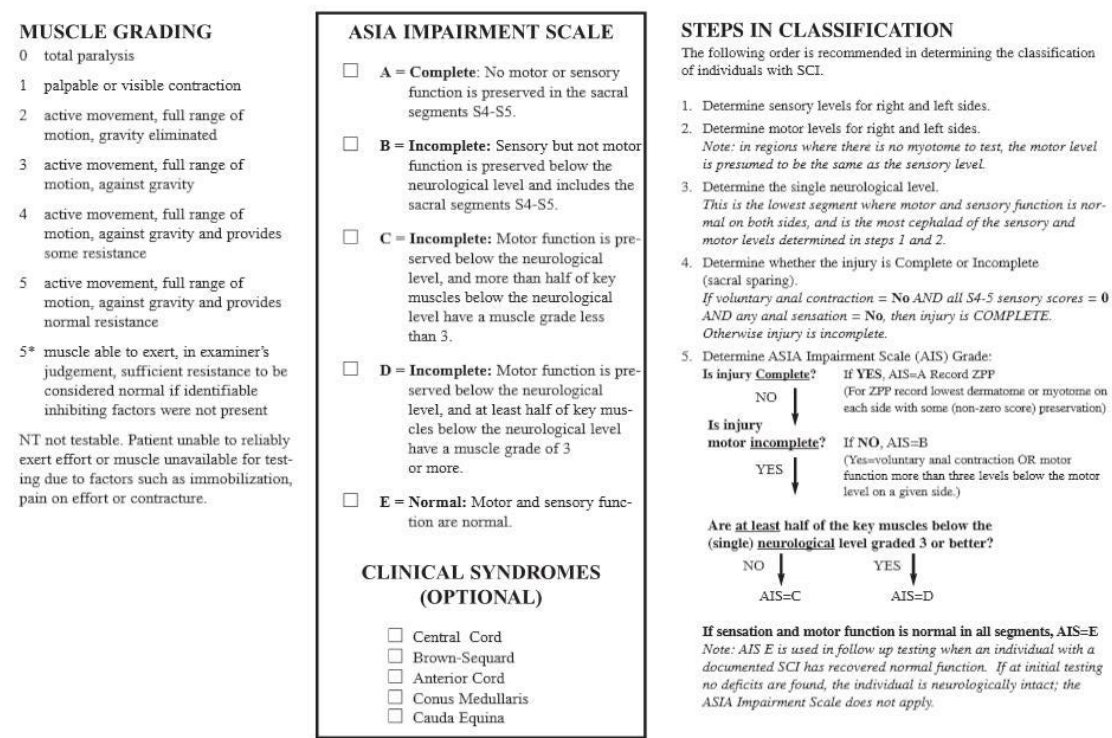

Figure 4: International Standards Worksheet (page 2). (S. C. Kirshblum et al., 2011) 
Spinal cord injuries are commonly separated into two groups based on the severity and level of injury. Impairment or loss of motor and/or sensory function in the thoracic, lumbar, or sacral segments of the spinal cord is referred to as paraplegia. Paraplegic subjects have arm function, but may have impaired function of the trunk, legs, and pelvic organs depending on the level of injury. Tetraplegia refers to impairment or loss of motor and/or sensory function in the cervical segments of the spinal cord. This may result in differing degrees of impairment of the four limbs as well as the trunk, legs, and pelvic organs (Chen et al., 2003; Marino, 2007; Waring et al., 2010). The most common type of SCI is incomplete tetraplegia (39.5\%), followed by complete paraplegia (22.1\%), incomplete paraplegia (21.7\%), and complete tetraplegia (16.3\%)(National Spinal Cord Injury Statistic Center, 2012). 


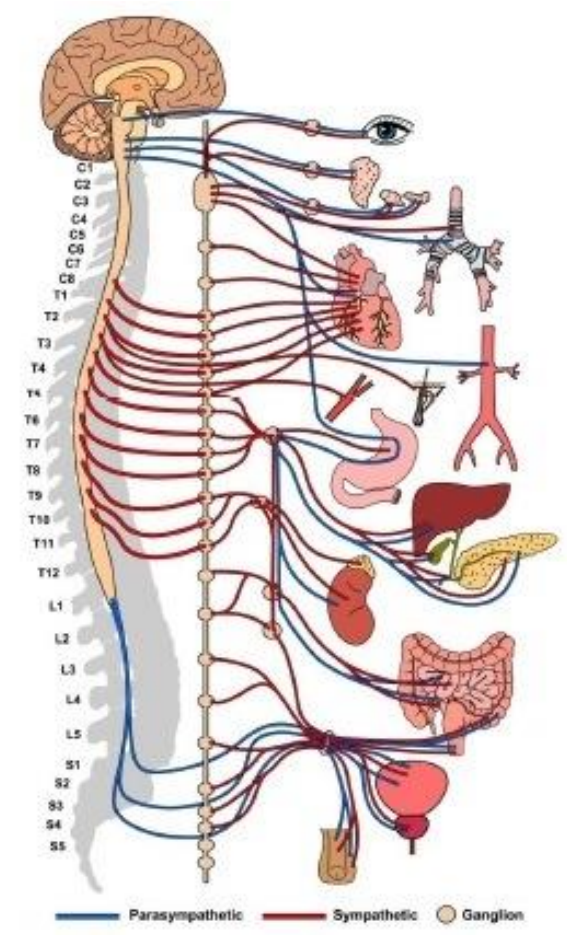

Figure 5: Schematic illustration of the major organs and areas innervated by the sympathetic and parasympathetic nervous system according to spinal cord level. Taken from asialearningcenter.org.

Individuals with SCI are often physically unfit, and those with paraplegia are slightly more fit than those with tetraplegia(Eggers et al., 2001). The cross-sectional area of muscle fiber declines by $40-50 \%$ after injury. This change in muscle tissue may be associated with an increased risk of coronary artery disease (Figoni, 2010; Garshick et al., 2005; Nash \& Dyson-Hudson, 2009; Phillips et al., 1998)and hyperlipidemia. There is also an increase in intramuscular fat, which may contribute to the onset of glucose intolerance and insulin dependence (Banerjea et al., 2008; McCully, Mulcahy, Ryan, \& Zhao, 2011). Additional secondary complications include pulmonary emboli, pain, and reduced mobility (Walter et al., 2002). Individuals with chronic SCI have lower resting metabolic rates (RMR), resting energy expenditure (REE), and $\mathrm{VO}_{2}$ peak(Buchholz \& Pencharz, 2004; Coutts, Rhodes, \& McKenzie, 1983; Myers, Lee, \& Kiratli, 2007; Phillips et al., 1998; Zurlo, Larson, Bogardus, \& Ravussin, 1990). 


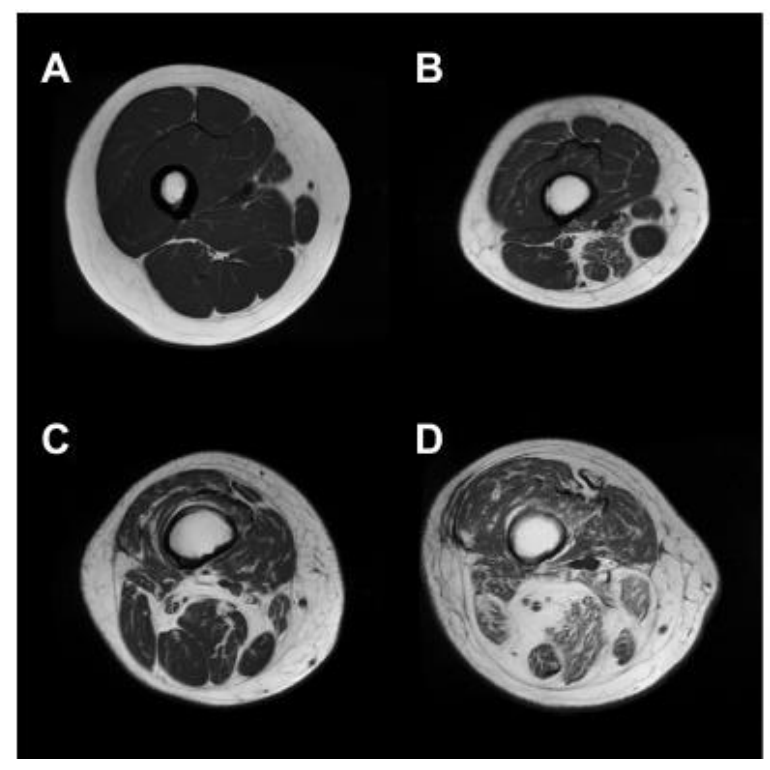

Figure 6: Representative T1-weighted images from the upper thigh of (A) able-bodied (AB) female, (B) female with spinal cord injury (SCI) and low muscle fat, (C) male with SCI and high muscle fat, and (D) diabetic male with SCI and high intramuscular fat. (McCully et al., 2011)

Spinal cord injury may also impact autonomic function (Krassioukov, 2006, 2009;

Krassioukov et al., 2012; Krassioukov \& Claydon, 2006; Sisto et al., 2012; West et al., 2012). The cranial parasympathetic nervous system will not be affected and will remain intact. However, the sacral parasympathetic system may be affected by a complete SCI. Thoracolumbar sympathetic nervous system function can be affected to a varying degree, possibly disturbing heart function and blood redistribution capacity during exercise (Krassioukov, 2006, 2012; Sisto et al., 2012; Theisen, 2012). For this reason, heart rate may not be an accurate mean to predict $\mathrm{VO}_{2}$ max in the SCI population. The 6-20 RPE scale has shown a strong positive correlation with RPE, heart rate, and $\mathrm{VO}_{2}$ max in healthy populations (Al-Rahamneh \& Eston, 2011a; Borg, 1982; Eston, Lamb, Parfitt, \& King, 2005) and in individuals with SCI (Al-Rahamneh \& Eston, 2011a, 2011b). Therefore, prediction of $\mathrm{VO}_{2}$ max based on RPE may be more reliable for the SCI population. 
Spinal cord injury often reduces participation in physical activity (Buchholz, McGillivray, \& Pencharz, 2003; Buchholz \& Pencharz, 2004; Dallmeijer, Hopman, van As, \& van der Woude, 1996; Fernhall, Heffernan, Jae, \& Hedrick, 2008; Hoffman, 1986; Jacobs \& Nash, 2004; Janssen, Dallmeijer, Veeger, \& van der Woude, 2002; Lavis, Scelza, \& Bockenek, 2007; Myers et al., 2007; Phillips et al., 1998) and decreases an individual's resting metabolic rate (Buchholz et al., 2003; Buchholz \& Pencharz, 2004; Hayes et al., 2005; McCully et al., 2011; Myers et al., 2007; Phillips et al., 1998; Price, 2010) which causes a major decrease in total daily energy expenditure. This decrease in total daily energy expenditure, combined with disorders of the autonomic nervous system commonly found in SCI patients (Garstang \& Miller-Smith, 2007; Karlsson, 2006; Krassioukov, 2009; Krassioukov \& Claydon, 2006; Teasell, Arnold, Krassioukov, \& Delaney, 2000; Theisen, 2012; West et al., 2012), causes an increase in percent body fat (Buchholz \& Pencharz, 2004; Flank, Wahman, Levi, \& Fahlstrom, 2012; Gorgey et al., 2012), as well as places this population at a much higher risk of chronic diseases like cardiovascular disease (Cowan \& Nash, 2010; Fernhall et al., 2008; Flank et al., 2012; Garshick et al., 2005; Myers et al., 2007; Svircev, 2009), obesity (Buchholz et al., 2003; Buchholz \& Pencharz, 2004; Fernhall et al., 2008; Flank et al., 2012; Garshick et al., 2005; Gater, 2007), and diabetes (Banerjea et al., 2008; Flank et al., 2012; Garshick et al., 2005).

Many chronic diseases such as type 2 diabetes, cardiovascular disease, and obesity are associated with lifestyle behaviors like maintaining a positive energy balance. This positive energy balance in otherwise healthy populations is caused by a sedentary lifestyle, increased caloric intake, a reduction in metabolism, or a mixture of these 
factors. Total daily energy expenditure and physical activity is inversely related to weight gain and body fat percentage. As an individual's daily energy expenditure decreases, over time their weight and percent body fat will increase due to the positive energy balance they maintain (Ravussin et al., 1988).

Exercise training individuals with spinal cord injury has shown positive results in relation to cardiovascular health and overall quality of life (Cowan \& Nash, 2010; Dobkin et al., 2007; Gorgey et al., 2012; Hettinga \& Andrews, 2008; Hicks et al., 2005; Hicks et al., 2003; Hoffman, 1986; Jacobs, Nash, \& Rusinowski, 2001; S. Kirshblum, 2004; Le Foll-de Moro, Tordi, Lonsdorfer, \& Lonsdorfer, 2005; L. Valent et al., 2010; L. Valent, Dallmeijer, Houdijk, Talsma, \& van der Woude, 2007; L. J. Valent et al., 2009; van Duijnhoven et al., 2010). The most accurate measurement of cardiovascular fitness in healthy individuals is through the measurement of oxygen consumption at an individual's maximal work rate $\left(\mathrm{VO}_{2} \max \right)$. $\mathrm{VO}_{2} \max$ is commonly used for exercise prescription as it gives the health professional an objective measurement of the cardiovascular fitness of an individual (Bruce et al., 1973; Noonan \& Dean, 2000; Pescatello, 2013; Pollack et al., 1980; Shephard et al., 1968). However, maximal effort tests cannot be done without the use of expensive equipment typically only found in labs, are time consuming, and cannot be conducted without a doctor's consent.

Tests estimating $\mathrm{VO}_{2} \max$ from submaximal levels of work are much affordable, do not require the patients to exercise to exhaustion, are typically safer, and are commonly used to estimate the maximal oxygen consumption of healthy populations (Noonan \& Dean, 2000; Pescatello, 2013). Most studies that have developed a submaximal exercise protocol for the SCI population have depended on stressing the 
cardiovascular system with only the upper body (Al-Rahamneh \& Eston, 2011a, 2011b; Borello-France et al., 2000; Hol et al., 2007; van Drongelen, Maas, Scheel-Sailer, \& Van Der Woude, 2009; Verellen, Meyer, Janssens, \& Vanlandewijck, 2012). However, the small and easily exhaustible muscles of the upper body often do not adequately stress the cardiovascular system, resulting in lower oxygen consumption values (Coutts et al., 1983; Eggers et al., 2001).

In a study comparing cardiovascular responses between able bodied individuals and individuals with spinal cord injury, Higuchi et al. (2006) found that passive walking resulted in similar values for oxygen consumption, pulmonary ventilation, and heart rate in individuals with SCI when compared to able bodied subjects. Therefore, even passive use of the muscles of the lower body may increase an individual with spinal cord injury's cardiovascular response to exercise. A total body recumbent stepper may be a feasible option that could potentially elicit the same cardiovascular responses to exercise as passive walking. Maximal tests using a total body recumbent stepper have been established for both able bodied individuals (Billinger, Loudon, \& Gajewski, 2008) and individuals with stroke (Billinger, Tseng, \& Kluding, 2008).

Al-Rahamneh and Eston (2011a) reported that a submaximal exercise protocol using an arm crank ergometer to estimate maximal oxygen consumption in individuals with SCI show high correlation with the directly measured values from a maximal test. Since RPE may be a more reliable indicator of cardiovascular stress in individuals with spinal cord injury than heart rate, the current study will attempt to establish a submaximal protocol based off of RPE using a total body recumbent stepper. 


\section{METHODS}

\section{Aims}

The purpose of this study is to validate a submaximal test to predict maximal oxygen consumption using RPE in individuals with spinal cord injury.

\section{Hypothesis}

1. Values of VO2 max estimated by a submaximal test in a total body recumbent stepper will show a strong positive correlation with the values of VO2peak obtained from a maximal graded exercise test.

\section{Experimental Design}

Participants with and without spinal cord injuries were invited to participate in this study. The study took place at The Frazier Rehab Institute. Each participant performed a graded exercise test (GXT) on a total body recumbent stepper (NuStep T4 ergometer, Ann Arbor, $\mathrm{MI})$ to measure peak oxygen consumption $\left(\mathrm{VO}_{2}\right.$ peak $)$ and a submaximal test to estimate $\mathrm{VO}_{2}$ max. The tests were separated by at least 48 hours and at most one week. The submaximal test was conducted first to avoid familiarization with the full RPE scale. Participants were asked to not perform any moderate or heavy exercise 12 hours prior to the test. Each test was conducted on the same total body recumbent stepper. The seat position was set so the subject had a slight bend in their knee at full extension. Arm handles were positioned to allow full extension without leaning forward in the seat. 
Oxygen consumption was analyzed with a Parvo Medic TrueOne 2400 (Sandy, UT). Analysis of the expired air occurred every 10 seconds. The cart was calibrated with a 3-liter syringe for flowmeter calibration and the ambient air measure for gas calibration at least 30 minutes before testing as recommended by the manufacturer's guidelines. Heart rate was recorded using a Polar heart rate monitor as well as by 3-lead EKG. RPE was recorded using the Borg 6-20 scale, which was explained to each participant using standardized instructions. Any questions the participant had were answered to insure full understanding. All variables such as gas consumption, respiratory exchange ratio, heart rate, $V_{\mathrm{E}}$, power output, and time were all kept out of the participant's sight during the test.

\section{Inclusion Criteria}

Able bodied individuals and individuals with chronic spinal cord injury (SCI) aged 18-65 in stable medical condition without cardiopulmonary disease were invited to participate in this study. Individuals with SCI that met the following inclusion criteria were included in the study:

- Have no:

- Painful musculoskeletal dysfunction.

- Unhealed fracture, contracture, pressure sore.

- Urinary tract infection.

- Clinically significant depression.

- Psychiatric disorders.

- Ongoing drug abuse. 
- Clear indications that the period of spinal shock is concluded which will be determined by the presence of muscle tone, deep tendon reflexes, and muscle spasms.

- Participants must have non-progressive SCI with injuries between spinal segments Cervical 2 to Sacral 5 and an American Spinal Injury Association Impairment Scale (AIS) classification of A-D.

- Participants must not be ventilator dependent for respiration.

- Participants will be excluded if there is a presence of:

- major cardiovascular or pulmonary disease

○ pregnancy

- endocrine disorders

○ malignancy

○ marked obesity

- lower extremity deep vein thrombosis

- Major gastrointestinal problems such as swallowing, or other major medical illness contraindicated for a maximal and submaximal exercise test, spirometry, or oxygen consumption test.

Prior to the study, potential participants will be evaluated by a physician, Dr. Williams, who will recommend or contraindicate participation.

\section{$\mathrm{VO}_{2}$ peak Test Protocol}

Participants warmed up for two minutes at a resistance of 1 and at 115 steps per minute (SPM) for able bodied subjects and 80 SPM for SCI subjects as these speeds have been validated (Billinger, Loudon, et al., 2008; Billinger, Tseng, et al., 2008). After the 
two minute warm up, the subjects immediately began the test at a resistance of 4 . Every two minutes, the resistance was increased until exhaustion. 20 seconds before the end of each stage, the subjects were asked to report their RPE. Blood pressure and heart rate were measured before warm up, immediately after the test, and 5 minutes posttest. The test was terminated when 1) the subject reports subjective fatigue and stops the test despite verbal encouragement, 2) the subject is no longer able to keep the SPM at or above 115 for able bodied subjects and 80 for SCI subjects, and 3) predicted maximum heart rate was reached.

\section{Submaximal Test Protocol}

Participants warmed up for two minutes at a resistance of 1 and at 115 SPM for able bodied subjects and 80 SPM for SCI subjects. The subjects were then asked to complete 5 two minute stages at RPEs of 9, 11, 13, 15, and 17. Every 30 seconds subjects were asked their RPE. If their RPE was anything other than the RPE assigned for that stage, resistance was adjusted. Watts and heart rate were all also taken every 30 seconds. Blood pressure and heart rate were measured before warm up, immediately after the test, and 5 minutes posttest. Subjects were instructed to cool down at a resistance of 1 and at their own pace for two minutes after blood pressure and heart rate were taken immediately posttest.

\section{Statistical Analysis}

Linear mixed effects models were fit using data from the submaximal test. The fixed effects were defined so that submaximal $\mathrm{VO}_{2}$ was modeled as a linear function of RPE and average wattage during the submaximal test. Random effects were defined for 
the intercept and RPE slope term. Estimates of the intercept and slope terms with 95\% confidence intervals were generated from the mixed effects model.

Predictions of maximum $\mathrm{VO}_{2}$ were generated from these models using the fixed effects equation and the best linear unbiased predictors (BLUP) of the random effects. For these predictions, we set $\mathrm{RPE}=20$ to correspond with the maximal test. Since the submaximal test terminates at $\mathrm{RPE}=17$, average wattage at $\mathrm{RPE}=20$ was not known and could not be used to predict maximum $\mathrm{VO}_{2}$ at an RPE of 20. A mixed effects model of average wattage onto RPE was fit to generate predicted average wattages at RPE 20. These predicted wattage values were subsequently used to generate predicted maximum $\mathrm{VO}_{2}$ values for each individual. As a secondary measure, we fit mixed effects models excluding the wattage term, and generated predicted maximum $\mathrm{VO}_{2}$ at $\mathrm{RPE}=20$ from these models. Pearson correlation coefficients and Lin's concordance correlation coefficient were calculated between observed and predicted $\mathrm{VO}_{2}$.

In an effort to determine the extent to which the submaximal test must be conducted, (i.e.) at what RPE the submaximal test can be terminated, models were fit for all of the submaximal test data (RPE 9 - 17), a subset of the data including only RPE 9 15, and another subset including only RPE 9 - 13. Predictions from each of these models were generated as described above, and the Pearson and Lin correlations between predicted and observed maximum $\mathrm{VO}_{2}$ was calculated. 


\section{RESULTS}

\section{Subject Characteristics}

\begin{tabular}{|c|c|c|c|c|c|c|c|c|c|}
\hline Subject & Age & Sex & Weight (kg) & Height (cm) & $\begin{array}{c}\text { Maximum } \\
\text { Reported RPE }\end{array}$ & RER & HR & Watts & Resistance \\
\hline N85 & 26 & $\mathrm{~F}$ & 67.1 & 162.6 & 20 & 1.29 & 196.0 & 147 & 7 \\
\hline N86 & 24 & M & 104.3 & 175.3 & 19 & 1.17 & 173.7 & 382.5 & 9 \\
\hline N87 & 24 & $\mathrm{~F}$ & 65.8 & 174.6 & 18 & 1.19 & 176.3 & 230.5 & 9 \\
\hline N88 & 37 & M & 102.1 & 177.8 & 20 & 1.19 & 191.8 & 251 & 8 \\
\hline N89 & 20 & M & 72.6 & 180.3 & 19 & 1.21 & 185.8 & 274.5 & 10 \\
\hline N84 & 29 & $\mathrm{~F}$ & 67.1 & 160.0 & 20 & 1.29 & 185.0 & 166.5 & 8 \\
\hline N69 & 30 & M & 83.0 & 175.3 & 19 & 1.16 & 165.8 & 294.5 & 9 \\
\hline N90 & 24 & M & 74.8 & 172.7 & 20 & 1.13 & 183.0 & 263 & 8 \\
\hline N91 & 29 & M & 96.2 & 185.4 & 20 & 1.04 & 169.3 & 259 & 10 \\
\hline N60 & 37 & $\mathrm{~F}$ & 65.5 & 175.3 & 19 & 1.07 & 176.0 & 176.5 & 8 \\
\hline \multicolumn{10}{|c|}{ Summary Mean (SD) } \\
\hline Males & $27.3(5.99)$ & 6 & $88.83(13.89)$ & $177.8(4.53)$ & $19.5(0.55)$ & $1.15(0.06)$ & $178.25(10.19)$ & 287.42 (48.97) & $9(0.89)$ \\
\hline Females & $29(5.72)$ & 4 & $66.38(0.85)$ & $168.13(7.96)$ & $19.25(0.96)$ & $1.21(0.11)$ & $183.33(9.42)$ & $180.13(35.75)$ & $8(0.82)$ \\
\hline All & $28(5.62)$ & & $79.85(15.55)$ & $173.93(7.58)$ & $19.4(0.70)$ & $1.17(0.08)$ & $180.28(9.70)$ & $244.5(69.48)$ & $8.6(0.97)$ \\
\hline
\end{tabular}

Table 2: Able Bodied Subject Characteristics

\begin{tabular}{|lcccccccccc|}
\hline & & & & & & \multicolumn{2}{c|}{ Maximum } \\
Subject & Age & Sex & Weight $(\mathbf{k g})$ & Height $(\mathbf{c m})$ & ASIA Score & Injury Level & Reported RPE & RER & Watts & Resistance \\
\hline A53 & 28 & M & 65.5 & 180.3 & A & T3 & 20 & 1.09 & 120 \\
C28 & 28 & M & 72.7 & 177.8 & C & T4-6 & 20 & 1.25 & 117 & 7 \\
\hline Average (SD) & 28 & & $69.1(5.1)$ & $179.1(1.8)$ & & & 20 & $1.17(0.12)$ & $118.5(2.12)$ & $8(1.4)$ \\
\hline
\end{tabular}

Table 3: SCI Subject Characteristics

Six male and five female able bodied subjects initially participated in the submaximal and maximal oxygen consumption tests. However, one female subject was not able to complete the two tests within seven days of each other and was training for a marathon. Therefore, her data was excluded from analysis due to her training increasing her recorded oxygen consumption during the maximal test. The average age of the ten remaining participants was 28 with a standard deviation of 5.62. The ages ranged from 20 years to 37 years old. The average RPE recorded at the end of the maximal test was 19.4 (SD: 0.70 ) with the lowest being 18 . Average respiratory exchange ratio at peak RPE was $1.17(0.08)$. Average heart rate was 180.28 (9.70) beats per minute. Average wattage of the participants at maximum RPE was $244.5 \mathrm{~W}$ (69.48) with a maximum of $382.5 \mathrm{~W}$ 
(Subject 2) and a minimum of $147 \mathrm{~W}$ (Subject 1). Two males with thoracic spinal cord injuries also participated in the submaximal and maximal oxygen consumption tests. Both reported a maximum RPE of 20 during the maximal test. Their average wattage at maximal RPE was 118.5 and the average RER was 1.17 .

\section{Experimental Conditions}

\begin{tabular}{|c|c|c|c|c|c|c|c|c|c|c|c|c|c|c|c|}
\hline & 6 & 7 & 8 & 9 & 10 & 11 & 12 & 13 & 14 & 15 & 16 & 17 & 18 & 19 & 20 \\
\hline Submax VO2 & & & & 14.8 & & 15.2 & & 19.60 & 29 & 28.9 & & 37.5 & 2000 & ?า & \\
\hline $\begin{array}{r}\text { Maximal VO2 } \\
\text { Submax Watts }\end{array}$ & & 10.9 & 14.96 & 89.5 & & $\begin{array}{l}18.12 \\
107.0\end{array}$ & 23.17 & 133.0 & 28.49 & $\begin{array}{c}33.4 \\
187.3\end{array}$ & & 233.3 & 38.98 & 42.42 & \\
\hline Maximal Watts & & 87.0 & 112.5 & & & 127.0 & 152.5 & & 191.5 & 214.5 & & & 256 & 274.5 & \\
\hline $\begin{array}{r}\text { Submax HR } \\
\text { Maximal HR }\end{array}$ & & 1012 & 107.67 & 102.0 & & $\begin{array}{l}105.5 \\
114.8\end{array}$ & 132.67 & 122.5 & 157.67 & $\begin{array}{l}147.3 \\
167.3\end{array}$ & & 167.7 & 178.67 & 18583 & \\
\hline
\end{tabular}

Table 4: $\mathrm{VO}_{2}$, watts, and heart rate values recorded and correlating RPE during subject N89's submaximal and maximal exercise tests

\begin{tabular}{|r|c|c|c|c|c|c|c|c|c|c|c|c|c|c|c|}
\hline & $\mathbf{6}$ & $\mathbf{7}$ & $\mathbf{8}$ & $\mathbf{9}$ & $\mathbf{1 0}$ & $\mathbf{1 1}$ & $\mathbf{1 2}$ & $\mathbf{1 3}$ & $\mathbf{1 4}$ & $\mathbf{1 5}$ & $\mathbf{1 6}$ & $\mathbf{1 7}$ & $\mathbf{1 8}$ & $\mathbf{1 9}$ & $\mathbf{2 0}$ \\
\hline $\begin{array}{l}\text { Submax VO2 } \\
\text { Maximal VO2 }\end{array}$ & 11.9 & & & 12.2 & 15.3 & 12.5 & & 15.3 & & 17.5 & & 20.3 & & & 18.1 \\
\hline $\begin{array}{l}\text { Submax Watts } \\
\text { Maximal Watts }\end{array}$ & 60.0 & & & 62.8 & & 70.5 & & 77.0 & & 89.5 & & 113.0 & & & 117.0 \\
\hline
\end{tabular}

Table 5: $\mathrm{VO}_{2}$, and watt values recorded and correlating RPE during subject $\mathrm{C} 28$ 's submaximal and maximal exercise tests

The two tables above are the results of four tests from two participants, one able bodied and the other with an SCI. Wattage was recorded four times during the submaximal test and two times during the maximal test. The listed $\mathrm{VO}_{2}$ is the average of the three highest oxygen consumption values during each stage. The SCI subject was only able to make it 30 seconds into his last stage before exhaustion, only giving two $\mathrm{VO}_{2}$ values.

\section{Mixed Effects Model Building - Technical Considerations}

The mixed effects models of the submaximal data were built progressively. The initial linear model of $\mathrm{VO}_{2}$ included RPE as the lone fixed effect and only random a intercept term. Adding a random RPE slope term significantly improved the fit of the model (ANOVA, $\mathrm{p}<.001$ ), and thus the random RPE slope term was included. The 
average wattage fixed effect was significant when added to the random RPE model ( $\mathrm{p}<$ .001) and was therefore included. A random wattage term did not significantly improve the fit of the model (ANOVA, $p>.13$ ) and was thus excluded. These findings defined the mixed effects model specification detailed in the methods section, and were consistent for each of the ranges of RPE tested (RPE 9-17, RPE 9-15, and RPE 9-13).

\section{Prediction Equations}

Estimates of the fixed effects terms (intercept, RPE slope, wattage slope) with 95\% confidence intervals are in the table below. Predictably, $\mathrm{VO}_{2}$ increased with RPE and wattage, although the rate at which $\mathrm{VO}_{2}$ increased with RPE varied substantially based on the subset of the data used, from 0.503 per RPE unit for the full data to 0.631 per RPE unit for the 9-15 RPE subset of the data. The rate at which $\mathrm{VO}_{2}$ increased with average wattage was observed to be lower for the subsets of the data (0.099 and 0.099) than for the full data (0.112).

\begin{tabular}{|c|c|c|c|}
\hline Data & Intercept & RPE Slope & $\begin{array}{c}\text { Wattage } \\
\text { Slope }\end{array}$ \\
\hline RPE 9-17 & $\begin{array}{c}-1.990 \\
(-3.694,-0.287)\end{array}$ & $\begin{array}{c}0.503 \\
(0.200,0.805)\end{array}$ & $\begin{array}{c}0.112 \\
(0.094,0.29)\end{array}$ \\
\hline RPE 9-15 & $\begin{array}{c}-1.854 \\
(-3.866,0.157) \\
\end{array}$ & $\begin{array}{c}0.631 \\
(0.314,0.948) \\
\end{array}$ & $\begin{array}{c}0.099 \\
(0.079,0.118)\end{array}$ \\
\hline RPE 9-13 & $\begin{array}{c}-0.613 \\
(-3.573,2.348)\end{array}$ & $\begin{array}{c}0.521 \\
(0.179,0.862)\end{array}$ & $\begin{array}{c}0.098 \\
(0.076,0.120)\end{array}$ \\
\hline
\end{tabular}

Table 6: Estimates of fixed effects terms based on watts and RPE with 95\% confidence intervals

The fixed effects equations defining $\mathrm{VO}_{2}$ as a linear function of $\mathrm{RPE}$ and wattage were defined based on the fixed effects estimates in the above table:

$\begin{array}{ll}\text { RPE 9-17: } & \mathrm{VO}_{2}=-1.990+0.503 * \mathrm{RPE}+0.112 * \text { Watts } \\ \text { RPE 9-15: } & \mathrm{VO}_{2}=-1.854+0.631 * \mathrm{RPE}+0.099 * \text { Watts } \\ \text { RPE 9-13: } & \mathrm{VO}_{2}=-0.613+0.521 * \mathrm{RPE}+0.098 * \text { Watts }\end{array}$


It should be noted that these equations provide population-level predictions rather than individualized predictions afforded by the random effects included in the model.

Specifically, the predicted maximum $\mathrm{VO}_{2}$ was generated using the above fixed intercepts and slopes as well as the BLUP of the random effects, (i.e.) the individual-level deviations from the intercept and RPE-slope terms. Because of this, these equations are not meant for general use in predicting maximum $\mathrm{VO}_{2}$ based on RPE and average wattage. Correlations between the population predictions of maximum $\mathrm{VO}_{2}$ based on the above equations and the observed maximum $\mathrm{VO}_{2}$ were much lower than those for the predictions that utilized the random effects detailed in the next section.

\section{RPE Only Model}

Average wattage was a significant predictor in the $\mathrm{VO}_{2}$ models of the submaximal test data, but pose a challenge in predicting maximum $\mathrm{VO}_{2}$, since the average wattage at $\mathrm{RPE}=20$ is unknown and must itself be predicted. Further, although average wattage was a significant predictor of $\mathrm{VO}_{2}$ for the submaximal data, it was not known if it contributed substantially to prediction of the observed maximum $\mathrm{VO}_{2}$. Therefore, mixed effects models without the average wattage fixed effect were fit. Estimates of the fixed effects for the intercept and RPE slope with $95 \%$ confidence intervals are provided below.

\begin{tabular}{|l|c|c|}
\hline Data & Intercept & RPE Slope \\
\hline Full data (RPE 9-17) & -4.986 & 1.998 \\
& $(-9.251,-0.721)$ & $(1.574,2.422)$ \\
\hline Sub data 1 (RPE 9-15) & -3.919 & 1.901 \\
& $(-8.046,0.208)$ & $(1.456,2.346)$ \\
\hline Sub data 2 (RPE 9-13) & -0.624 & 1.582 \\
& $(-4.805,3.557)$ & $(1.129,2.035)$ \\
\hline
\end{tabular}

Table 7: Estimates of fixed effects based on RPE only with $95 \%$ confidence intervals 
Fixed effects equations for predicting $\mathrm{VO}_{2}$ from the RPE-Only models are below. As before, the actual predictions include the BLUP of the random effects (deviations from the intercept and slope, per patient) and are only partially generated from these equations.

$\begin{array}{ll}\text { RPE 9-17: } & \mathrm{VO}_{2}=-4.986+1.998 * \mathrm{RPE} \\ \text { RPE 9-15: } & \mathrm{VO}_{2}=-3.919+1.901 * \mathrm{RPE} \\ \text { RPE 9-13: } & \mathrm{VO}_{2}=-0.624+1.582 * \mathrm{RPE}\end{array}$

Accuracy of Predicted $\mathrm{VO}_{2}$ Max

The table below lists the observed maximum $\mathrm{VO}_{2}$ and maximum $\mathrm{VO}_{2}$ predicted from each subset of the data with each $\mathrm{VO}_{2}$ model. Correlation and concordance coefficients and $95 \%$ confidence intervals are provided for each of the predictions. Predictions offered by the full data (RPE 9-17) correlated well with observed values. Correlations for the RPE + Watts and RPE-Only model exceeded 0.86 and concordance correlations exceeded 0.81 . Substantial accuracy was lost in using only RPE 9-15 and RPE 9-13 in prediction, as correlation coefficients were reduced from the correlations exhibited for the RPE 9-17 predictions. It was noteworthy that the correlation exhibited by the RPE-Only predictions $(r=0.86)$ was only slightly and non-significantly $(\mathrm{p}=.89)$ lower than the correlation exhibited by the RPE + Watts predictions $(r=0.88)$. 


\begin{tabular}{|c|c|c|c|c|c|c|c|}
\hline \multirow[b]{2}{*}{ Subject } & \multirow[b]{2}{*}{ Observed } & \multicolumn{2}{|c|}{ RPE 9-17 } & \multicolumn{2}{|c|}{ RPE 9-15 } & \multicolumn{2}{|c|}{ RPE 9-13 } \\
\hline & & $\begin{array}{l}\text { RPE + } \\
\text { Watts }\end{array}$ & RPE-Only & $\begin{array}{l}\text { RPE + } \\
\text { Watts }\end{array}$ & $\begin{array}{l}\text { RPE- } \\
\text { Only }\end{array}$ & $\begin{array}{l}\text { RPE + } \\
\text { Watts }\end{array}$ & $\begin{array}{l}\text { RPE- } \\
\text { Only }\end{array}$ \\
\hline N69 & 38.1 & 41.9 & 40.9 & 43.5 & 40.6 & 35.2 & 34.4 \\
\hline N60 & 30.8 & 31.7 & 32.3 & 29.7 & 29.9 & 28.3 & 26.7 \\
\hline N84 & 27.7 & 29.3 & 29.3 & 28.6 & 29.1 & 28.5 & 29.4 \\
\hline N85 & 24.8 & 19.3 & 19.1 & 18.7 & 19.4 & 20.7 & 20.3 \\
\hline N86 & 36.1 & 42.3 & 43.0 & 47.2 & 47.1 & 48.2 & 48.6 \\
\hline N87 & 38.2 & 42.5 & 42.5 & 39.0 & 40.7 & 30.1 & 33.6 \\
\hline N88 & 25.6 & 31.2 & 32.2 & 33.2 & 35.0 & 34.4 & 33.6 \\
\hline N89 & 42.4 & 41.8 & 41.8 & 37.3 & 36.7 & 29.1 & 28.7 \\
\hline N90 & 35.3 & 33.2 & 33.1 & 30.9 & 30.9 & 26.9 & 26.6 \\
\hline N91 & 35.4 & 36.6 & 35.6 & 32.8 & 31.6 & 28.8 & 28.2 \\
\hline Mean (SD) & $33.4(5.9)$ & $34.5(7.6)$ & $35.0(7.5)$ & $34.1(8.1)$ & $34.1(7.2)$ & $31.0(7.2)$ & $31.0(0.2)$ \\
\hline $\begin{array}{l}\text { Correlation } \\
\text { Concordance }\end{array}$ & - & $\begin{array}{c}0.88 \\
(0.57,0.97) \\
0.83 \\
(0.53,0.95) \\
\end{array}$ & $\begin{array}{c}0.86 \\
(0.49,0.97) \\
0.81 \\
(0.47,0.94) \\
\end{array}$ & $\begin{array}{c}0.71 \\
(0.14,0.92) \\
0.67 \\
(0.18,0.89) \\
\end{array}$ & $\begin{array}{c}0.65 \\
(0.04,0.91) \\
0.63 \\
(0.08,0.88) \\
\end{array}$ & $\begin{array}{c}0.30 \\
(-0.41,0.78) \\
0.27 \\
(-0.34,0.72) \\
\end{array}$ & $\begin{array}{c}0.33 \\
(-0.37,0.80) \\
0.30 \\
(-0.31,0.74) \\
\end{array}$ \\
\hline
\end{tabular}

Table 8: Observed and predicted $\mathrm{VO}_{2}$ from RPE 9-17, 9-15, and 9-13

The residual standard error for predicting maximum $\mathrm{VO}_{2}$ from the RPE-Only, 917 mixed effects model was 2.09 , indicating that $95 \%$ confidence intervals for prediction would vary approximately 4.09 in either direction from the prediction. Six of the 10 confidence intervals for predicted maximum $\mathrm{VO}_{2}$ contained the observed maximum $\mathrm{VO}_{2}$ in our sample. Further, six of the 10 predicted maximum $\mathrm{VO}_{2}$ were within $10 \%$ of the observed values. Residual standard errors and confidence interval coverage rates were not calculated for other models - the RPE-Only model did not significantly differ in predictive accuracy from the RPE + Watts model and models using subsets of the data (RPE 9-15 and 9-13) were not sufficiently accurate in predicting maximum $\mathrm{VO}_{2}$. 

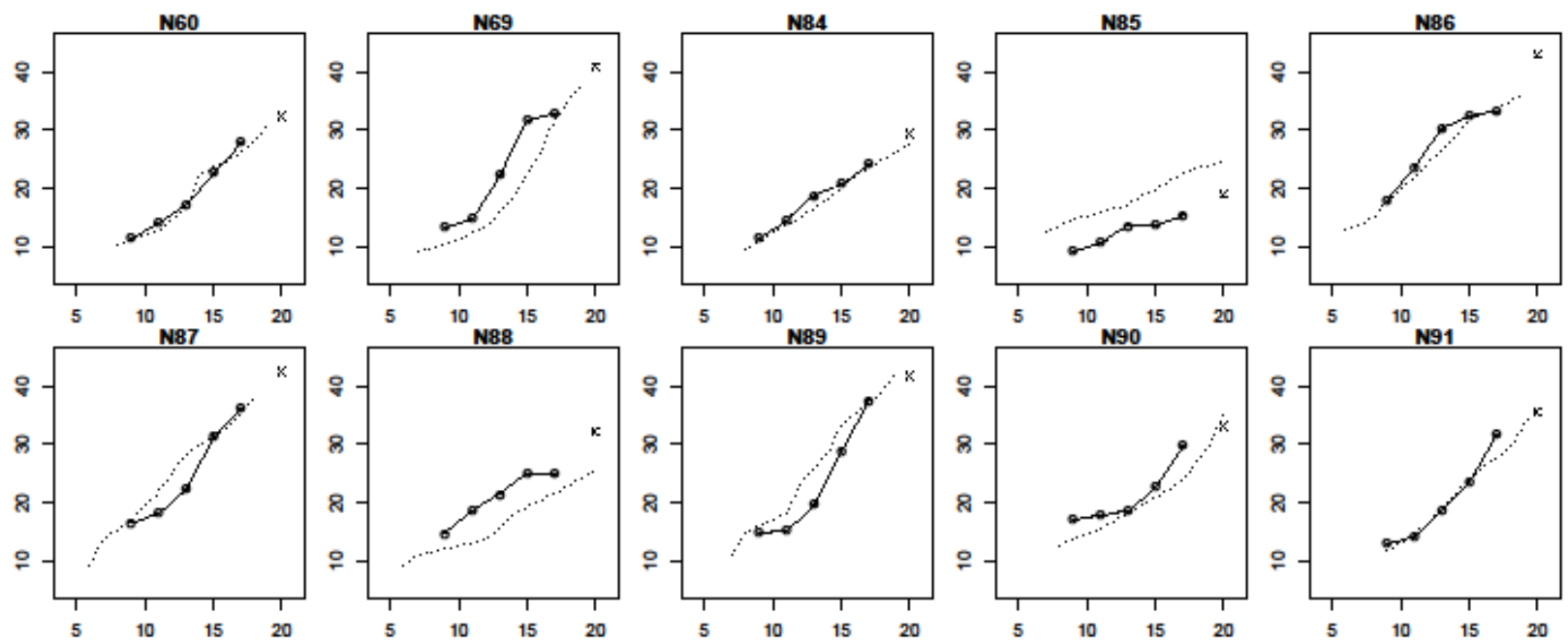

Figure 7: Observed $\mathrm{VO}_{2}$ from the submaximal exercise test (solid lines with dots) and maximal exercise test (dashed lines) tests. Marked X's indicate $\mathrm{VO}_{2}$ max predicted from the submaximal data.

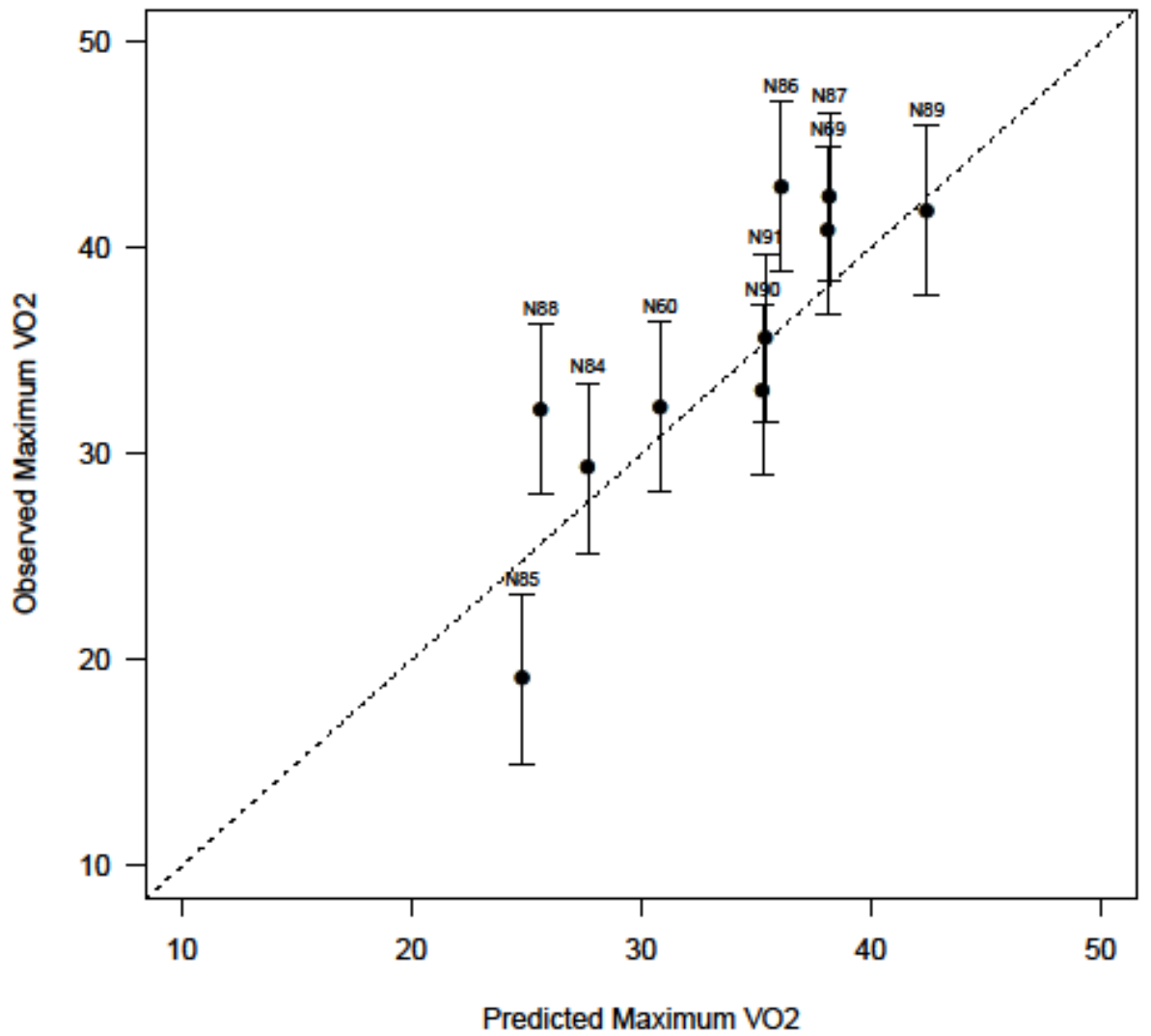

Figure 8: Observed vs. Predicted $\mathrm{VO}_{2}$ max. Bars from points represent $95 \%$ confidence intervals of prediction. Observations for which confidence interval bars cross the dashed line are those for which the observed maximum $\mathrm{VO}_{2}$ was contained in the $95 \%$ confidence. 


\section{CONCLUSION}

The results indicate that prediction of $\mathrm{VO}_{2} \mathrm{max}$ from an RPE-based protocol is feasible and can produce reliable predicted $\mathrm{VO}_{2}$ max values in the able bodied population. This is in agreement with previous studies on RPE and $\mathrm{VO}_{2}$ max prediction (AlRahamneh \& Eston, 2011a, 2011b; Eston et al., 2005). However, unlike what AlRahamneh and Eston (2011a) found, ending the test at RPE 13 or RPE 15 results in a significant loss of accuracy in predicting $\mathrm{VO}_{2} \max$. As a result, future tests must run until RPE 17 with further examination of ending the tests at lower RPEs.

Also note that the regression equations developed in this study are based solely on the 10 able bodied subjects tested and are not intended for widespread use in either SCI or able bodied populations. If a healthcare professional wished to use this protocol, they should plot that specific subject's $\mathrm{VO}_{2}$ and RPE values and develop their own linear regression equation to predict $\mathrm{VO}_{2}$ max by extrapolating out to RPE 20 . The prediction equations accounting for watts did give values that were better correlated to the directly measured values than the equations based solely on RPE. However, the small increase in correlation (.88 vs. .86) was not statistically significant. The inclusion of watts in future prediction equations should be considered optional. In fact, including watts may result in an additional source of error in the predicted values since an estimation of watts at RPE 20 would also be necessary.

This study is a proof of concept of the feasibility to use a submaximal test protocol using a total body recumbent stepper to predict $\mathrm{VO}_{2} \mathrm{max}$ in able bodied 
individuals. Additionally, this study shows evidence of feasibility in one individual with motor complete and one subject with motor incomplete SCI. Future directions include creating prediction equations for a larger group of individuals with different levels and severity of SCI. 


\section{REFERENCES}

Al-Rahamneh, H. Q., \& Eston, R. G. (2011a). Prediction of peak oxygen consumption from the ratings of perceived exertion during a graded exercise test and ramp exercise test in able-bodied participants and paraplegic persons. Arch Phys Med Rehabil, 92(2), 277-283. doi: 10.1016/j.apmr.2010.10.017

Al-Rahamneh, H. Q., \& Eston, R. G. (2011b). The validity of predicting peak oxygen uptake from a perceptually guided graded exercise test during arm exercise in paraplegic individuals. Spinal Cord, 49(3), 430-434. doi: 10.1038/sc.2010.139

Banerjea, R., Sambamoorthi, U., Weaver, F., Maney, M., Pogach, L. M., \& Findley, T. (2008). Risk of stroke, heart attack, and diabetes complications among veterans with spinal cord injury. Arch Phys Med Rehabil, 89(8), 1448-1453. doi: 10.1016/j.apmr.2007.12.047

Billinger, S. A., Loudon, J. K., \& Gajewski, B. J. (2008). Validity of a total body recumbent stepper exercise test to assess cardiorespiratory fitness. J Strength Cond Res, 22(5), 1556-1562. doi: 10.1519/JSC.0b013e3181739dd7

Billinger, S. A., Tseng, B. Y., \& Kluding, P. M. (2008). Modified total-body recumbent stepper exercise test for assessing peak oxygen consumption in people with chronic stroke. Phys Ther, 88(10), 1188-1195. doi: 10.2522/ptj.20080072

Blair, S. N., Kohl, H. W., 3rd, Barlow, C. E., Paffenbarger, R. S., Jr., Gibbons, L. W., \& Macera, C. A. (1995). Changes in physical fitness and all-cause mortality. A prospective study of healthy and unhealthy men. JAMA, 273(14), 1093-1098.

Borello-France, Diane, Rosen, Scott, Young, Anne Beirne, Wagner, Suzanne, Gregg, Heidi, Hudak, Debra, \& Gallek, Patricia. (2000). The Relationship Between Perceived Exertion and Heart Rate During Arm Crank Exercise in Individuals with Paraplegia. Journal of Neurologic Physical Therapy, 24(3), 94-100.

Borg, G. A. (1982). Psychophysical bases of perceived exertion. Med Sci Sports Exerc, 14(5), 377-381.

Brooks, George Austin, Fahey, Thomas Davin, \& Baldwin, Kenneth M. (2007). Exercise physiology : human bioenergetics and its applications. Boston, Md. [u.a.]: McGraw-Hill Higher Education.

Brown, R., DiMarco, A. F., Hoit, J. D., \& Garshick, E. (2006). Respiratory dysfunction and management in spinal cord injury. Respir Care, 51(8), 853-868;discussion 869-870.

Bruce, R. A., Kusumi, F., \& Hosmer, D. (1973). Maximal oxygen intake and nomographic assessment of functional aerobic impairment in cardiovascular disease. Am Heart J, 85(4), 546-562.

Buchholz, A. C., McGillivray, C. F., \& Pencharz, P. B. (2003). Physical activity levels are low in free-living adults with chronic paraplegia. Obes Res, 11(4), 563-570. doi: 10.1038/oby.2003.79

Buchholz, A. C., \& Pencharz, P. B. (2004). Energy expenditure in chronic spinal cord injury. Curr Opin Clin Nutr Metab Care, 7(6), 635-639. 
Caspersen, C. J., Powell, K. E., \& Christenson, G. M. (1985). Physical activity, exercise, and physical fitness: definitions and distinctions for health-related research.

Public Health Rep, 100(2), 126-131.

Chen, C. L., Yeung, K. T., Bih, L. I., Wang, C. H., Chen, M. I., \& Chien, J. C. (2003). The relationship between sitting stability and functional performance in patients with paraplegia. Arch Phys Med Rehabil, 84(9), 1276-1281.

Cohen, Barbara J., \& Memmler, Ruth Lundeen. (2013). Memmler's structure and function of the human body. Philadelphia, Pa.; London: Lippincott Williams \& Wilkins.

Coutts, K. D., Rhodes, E. C., \& McKenzie, D. C. (1983). Maximal exercise responses of tetraplegics and paraplegics. J Appl Physiol, 55(2), 479-482.

Cowan, R. E., \& Nash, M. S. (2010). Cardiovascular disease, SCI and exercise: unique risks and focused countermeasures. Disabil Rehabil, 32(26), 2228-2236. doi: 10.3109/09638288.2010.491579

Dallmeijer, A. J., Hopman, M. T., van As, H. H., \& van der Woude, L. H. (1996). Physical capacity and physical strain in persons with tetraplegia; the role of sport activity. Spinal Cord, 34(12), 729-735.

Dobkin, B., Barbeau, H., Deforge, D., Ditunno, J., Elashoff, R., Apple, D., . . Spinal Cord Injury Locomotor Trial, Group. (2007). The evolution of walking-related outcomes over the first 12 weeks of rehabilitation for incomplete traumatic spinal cord injury: the multicenter randomized Spinal Cord Injury Locomotor Trial. Neurorehabil Neural Repair, 21(1), 25-35. doi: 10.1177/1545968306295556

Eggers, L., Carson, C., Evans, K., Swank, A. M., Adams, K. J., Barnard, K. L., \& Berning, J. (2001). Limiting factors for increasing VO2 peak for individuals with spinal cord injury. Clinical Exercise Physiology, 3(1), 10-16.

Eston, R. G., Lamb, K. L., Parfitt, G., \& King, N. (2005). The validity of predicting maximal oxygen uptake from a perceptually-regulated graded exercise test. Eur J Appl Physiol, 94(3), 221-227. doi: 10.1007/s00421-005-1327-2

Fernhall, B., Heffernan, K., Jae, S. Y., \& Hedrick, B. (2008). Health implications of physical activity in individuals with spinal cord injury: a literature review. $J$ Health Hum Serv Adm, 30(4), 468-502.

Figoni, S.F. (2010). Spinal Cord Disabilities: Paraplegia and Tetraplegia. In J. K. Ehrman (Ed.), ACSM's resource manual for Guidelines for exercise testing and prescription (6 ed., pp. 298-303): Wolters Kluwer Health/Lippincott Williams \& Wilkins.

Flank, P., Wahman, K., Levi, R., \& Fahlstrom, M. (2012). Prevalence of risk factors for cardiovascular disease stratified by body mass index categories in patients with wheelchair-dependent paraplegia after spinal cord injury. J Rehabil Med, 44(5), 440-443. doi: 10.2340/16501977-0964

Garshick, E., Kelley, A., Cohen, S. A., Garrison, A., Tun, C. G., Gagnon, D., \& Brown, R. (2005). A prospective assessment of mortality in chronic spinal cord injury. Spinal Cord, 43(7), 408-416. doi: 10.1038/sj.sc.3101729

Garstang, S. V., \& Miller-Smith, S. A. (2007). Autonomic nervous system dysfunction after spinal cord injury. Phys Med Rehabil Clin N Am, 18(2), 275-296, vi-vii. doi: 10.1016/j.pmr.2007.02.003 
Gater, D. R., Jr. (2007). Obesity after spinal cord injury. Phys Med Rehabil Clin N Am, 18(2), 333-351, vii. doi: 10.1016/j.pmr.2007.03.004

Gorgey, A. S., Harnish, C. R., Daniels, J. A., Dolbow, D. R., Keeley, A., Moore, J., \& Gater, D. R. (2012). A report of anticipated benefits of functional electrical stimulation after spinal cord injury. J Spinal Cord Med, 35(2), 107-112. doi: 10.1179/204577212X13309481546619

Haskell, W. L., Lee, I., Pate, R. R., Powell, K. E., Blair, S. N., Franklin, B. A., . . . Bauman, A. (2007). Physical activity and public health: updated recommendation for adults from the American College of Sports Medicine and the American Heart Association. Medicine and science in sports and exercise, 39(8), 1423.

Hayes, A. M., Myers, J. N., Ho, M., Lee, M. Y., Perkash, I., \& Kiratli, B. J. (2005). Heart rate as a predictor of energy expenditure in people with spinal cord injury. $J$ Rehabil Res Dev, 42(5), 617-624.

Hettinga, D. M., \& Andrews, B. J. (2008). Oxygen consumption during functional electrical stimulation-assisted exercise in persons with spinal cord injury: implications for fitness and health. Sports Med, 38(10), 825-838.

Hicks, A. L., Adams, M. M., Martin Ginis, K., Giangregorio, L., Latimer, A., Phillips, S. M., \& McCartney, N. (2005). Long-term body-weight-supported treadmill training and subsequent follow-up in persons with chronic SCI: effects on functional walking ability and measures of subjective well-being. Spinal Cord, 43(5), 291-298. doi: 10.1038/sj.sc.3101710

Hicks, A. L., Martin, K. A., Ditor, D. S., Latimer, A. E., Craven, C., Bugaresti, J., \& McCartney, N. (2003). Long-term exercise training in persons with spinal cord injury: effects on strength, arm ergometry performance and psychological wellbeing. Spinal Cord, 41(1), 34-43. doi: 10.1038/sj.sc.3101389

Higuchi, Y., Kitamura, S., Kawashima, N., Nakazawa, K., Iwaya, T., \& Yamasaki, M. (2006). Cardiorespiratory responses during passive walking-like exercise in quadriplegics. Spinal Cord, 44(8), 480-486. doi: 10.1038/sj.sc.3101875

Hoffman, M. D. (1986). Cardiorespiratory fitness and training in quadriplegics and paraplegics. Sports Med, 3(5), 312-330.

Hol, A. T., Eng, J. J., Miller, W. C., Sproule, S., \& Krassioukov, A. V. (2007). Reliability and validity of the six-minute arm test for the evaluation of cardiovascular fitness in people with spinal cord injury. Arch Phys Med Rehabil, 88(4), 489-495. doi: 10.1016/j.apmr.2006.12.044

Jacobs, P. L., \& Nash, M. S. (2004). Exercise recommendations for individuals with spinal cord injury. Sports Med, 34(11), 727-751.

Jacobs, P. L., Nash, M. S., \& Rusinowski, J. W. (2001). Circuit training provides cardiorespiratory and strength benefits in persons with paraplegia. Med Sci Sports Exerc, 33(5), 711-717.

Janssen, T. W., Dallmeijer, A. J., Veeger, D. J., \& van der Woude, L. H. (2002). Normative values and determinants of physical capacity in individuals with spinal cord injury. J Rehabil Res Dev, 39(1), 29-39.

Jenkins, Gail W., Kemnitz, Christopher P., \& Tortora, Gerard J. (2007). Anatomy and physiology : from science to life. Hoboken, NJ: Wiley. 
Karlsson, A. K. (2006). Autonomic dysfunction in spinal cord injury: clinical presentation of symptoms and signs. Prog Brain Res, 152, 1-8. doi: 10.1016/S0079-6123(05)52034-X

Kirshblum, S. (2004). New rehabilitation interventions in spinal cord injury. J Spinal Cord Med, 27(4), 342-350.

Kirshblum, S. C., Burns, S. P., Biering-Sorensen, F., Donovan, W., Graves, D. E., Jha, A., ... Waring, W. (2011). International standards for neurological classification of spinal cord injury (revised 2011). J Spinal Cord Med, 34(6), 535-546. doi: 10.1179/204577211X13207446293695

Kodama, S., Saito, K., Tanaka, S., Maki, M., Yachi, Y., Asumi, M., . . Sone, H. (2009). Cardiorespiratory Fitness as a Quantitative Predictor of All-Cause Mortality and Cardiovascular Events in Healthy Men and Women A Meta-analysis. JamaJournal of the American Medical Association, 301(19), 2024-2035.

Krassioukov, A. (2006). Which pathways must be spared in the injured human spinal cord to retain cardiovascular control? Prog Brain Res, 152, 39-47. doi: 10.1016/S0079-6123(05)52003-X

Krassioukov, A. (2009). Autonomic function following cervical spinal cord injury. Respir Physiol Neurobiol, 169(2), 157-164. doi: 10.1016/j.resp.2009.08.003

Krassioukov, A. (2012). Autonomic dysreflexia: current evidence related to unstable arterial blood pressure control among athletes with spinal cord injury. Clin J Sport Med, 22(1), 39-45. doi: 10.1097/JSM.0b013e3182420699

Krassioukov, A., Biering-Sorensen, F., Donovan, W., Kennelly, M., Kirshblum, S., Krogh, K., .. . Autonomic Standards Committee of the American Spinal Injury Association/International Spinal Cord, Society. (2012). International standards to document remaining autonomic function after spinal cord injury. J Spinal Cord Med, 35(4), 201-210. doi: 10.1179/1079026812Z.00000000053

Krassioukov, A., \& Claydon, V. E. (2006). The clinical problems in cardiovascular control following spinal cord injury: an overview. Prog Brain Res, 152, 223-229. doi: 10.1016/S0079-6123(05)52014-4

Lavis, T. D., Scelza, W. M., \& Bockenek, W. L. (2007). Cardiovascular health and fitness in persons with spinal cord injury. Phys Med Rehabil Clin N Am, 18(2), 317-331, vii. doi: 10.1016/j.pmr.2007.03.003

Le Foll-de Moro, D., Tordi, N., Lonsdorfer, E., \& Lonsdorfer, J. (2005). Ventilation efficiency and pulmonary function after a wheelchair interval-training program in subjects with recent spinal cord injury. Arch Phys Med Rehabil, 86(8), 15821586. doi: 10.1016/j.apmr.2005.03.018

Marino, R. J. (2007). Domains of outcomes in spinal cord injury for clinical trials to improve neurological function. J Rehabil Res Dev, 44(1), 113-122.

McCully, K. K., Mulcahy, T. K., Ryan, T. E., \& Zhao, Q. (2011). Skeletal muscle metabolism in individuals with spinal cord injury. J Appl Physiol, 111(1), 143148. doi: 10.1152/japplphysiol.00094.2011

Myers, J., Lee, M., \& Kiratli, J. (2007). Cardiovascular disease in spinal cord injury: an overview of prevalence, risk, evaluation, and management. Am J Phys Med Rehabil, 86(2), 142-152. doi: 10.1097/PHM.0b013e31802f0247 
Nash, Mark S., \& Dyson-Hudson, Trevor A. (2009). Guideline-Driven Assessment of Cardiovascular Disease and Related Risks After Spinal Cord Injury. Topics in Spinal Cord Injury Rehabilitation, 14(3), 32-45. doi: 10.1310/sci1403-32

National Spinal Cord Injury Statistic Center. (2012). Spinal cord injury facts and figures at a glance. J Spinal Cord Med, 35(1), 68-69. doi:

$10.1179 / 204577212 X 13237783484262$

Noonan, V., \& Dean, E. (2000). Submaximal exercise testing: clinical application and interpretation. Phys Ther, 80(8), 782-807.

Paffenbarger Jr, Ralph S, Hyde, Robert T, Wing, Alvin L, Lee, I-Min, Jung, Dexter L, \& Kampert, James B. (1993). The association of changes in physical-activity level and other lifestyle characteristics with mortality among men. New England Journal of Medicine, 328(8), 538-545.

Pate, R. R., Pratt, M., Blair, S. N., Haskell, W. L., Macera, C. A., Bouchard, C., . . et al. (1995). Physical activity and public health. A recommendation from the Centers for Disease Control and Prevention and the American College of Sports Medicine. JAMA, 273(5), 402-407.

Pescatello, L.S. (2013). ACSM's Guidelines for Exercise Testing and Prescription (R. Arena, D. Riebe \& P. D. Thompson Eds. 9 ed.): Wolters Kluwer/Lippincott Williams \& Wilkins Health.

Phillips, W. T., Kiratli, B. J., Sarkarati, M., Weraarchakul, G., Myers, J., Franklin, B. A., ... Froelicher, V. (1998). Effect of spinal cord injury on the heart and cardiovascular fitness. Curr Probl Cardiol, 23(11), 641-716.

Pollack, M. L., Schmidt, D. H., \& Jackson, A. S. (1980). Measurement of cardiorespiratory fitness and body composition in the clinical setting. Compr Ther, 6(9), 12-27.

Powers, Scott K., \& Howley, Edward T. (2009). Exercise physiology : theory and application to fitness and performance. New York, NY: McGraw-Hill Higher Education.

Price, M. (2010). Energy expenditure and metabolism during exercise in persons with a spinal cord injury. Sports Med, 40(8), 681-696. doi: 10.2165/11531960000000000-00000

Ravussin, E., Lillioja, S., Knowler, W. C., Christin, L., Freymond, D., Abbott, W. G., . . . Bogardus, C. (1988). Reduced rate of energy expenditure as a risk factor for body-weight gain. $N$ Engl J Med, 318(8), 467-472. doi:

10.1056/NEJM198802253180802

Shephard, R. J., Allen, C., Benade, A. J. S., Davies, C. T. M., Di Prampero, P. E., Hedman, R., . . . Simmons, R. (1968). The maximum oxygen intake: An international reference standard of cardio-respiratory fitness. Bulletin of the World Health Organization, 38(5), 757.

Sisto, S. A., Lorenz, D. J., Hutchinson, K., Wenzel, L., Harkema, S. J., \& Krassioukov, A. (2012). Cardiovascular status of individuals with incomplete spinal cord injury from 7 NeuroRecovery Network rehabilitation centers. Arch Phys Med Rehabil, 93(9), 1578-1587. doi: 10.1016/j.apmr.2012.04.033

Svircev, J. N. (2009). Cardiovascular disease in persons with spinal cord dysfunction-an update on select topics. Phys Med Rehabil Clin N Am, 20(4), 737-747. doi: 10.1016/j.pmr.2009.06.012 
Teasell, R. W., Arnold, J. M., Krassioukov, A., \& Delaney, G. A. (2000). Cardiovascular consequences of loss of supraspinal control of the sympathetic nervous system after spinal cord injury. Arch Phys Med Rehabil, 81(4), 506-516. doi: $10.1053 / \mathrm{mr} .2000 .3848$

Theisen, D. (2012). Cardiovascular determinants of exercise capacity in the Paralympic athlete with spinal cord injury. Exp Physiol, 97(3), 319-324. doi:

10.1113/expphysiol.2011.063016

Valent, L., Dallmeijer, A., Houdijk, H., Slootman, H. J., Janssen, T. W., \& Van Der Woude, L. H. (2010). Effects of hand cycle training on wheelchair capacity during clinical rehabilitation in persons with a spinal cord injury. Disabil Rehabil, 32(26), 2191-2200. doi: 10.3109/09638288.2010.509461

Valent, L., Dallmeijer, A., Houdijk, H., Talsma, E., \& van der Woude, L. (2007). The effects of upper body exercise on the physical capacity of people with a spinal cord injury: a systematic review. Clin Rehabil, 21(4), 315-330. doi: $10.1177 / 0269215507073385$

Valent, L. J., Dallmeijer, A. J., Houdijk, H., Slootman, H. J., Janssen, T. W., Post, M. W., $\&$ van der Woude, L. H. (2009). Effects of hand cycle training on physical capacity in individuals with tetraplegia: a clinical trial. Phys Ther, 89(10), 10511060. doi: $10.2522 /$ ptj.20080340

van Drongelen, S., Maas, J. C., Scheel-Sailer, A., \& Van Der Woude, L. H. (2009). Submaximal arm crank ergometry: Effects of crank axis positioning on mechanical efficiency, physiological strain and perceived discomfort. J Med Eng Technol, 33(2), 151-157. doi: 10.1080/13561820802565676

van Duijnhoven, N., Hesse, E., Janssen, T., Wodzig, W., Scheffer, P., \& Hopman, M. (2010). Impact of exercise training on oxidative stress in individuals with a spinal cord injury. Eur J Appl Physiol, 109(6), 1059-1066. doi: 10.1007/s00421-0101398-6

VanPutte, C.L., Seeley, R.R., Regan, J.L., \& Russo, A.F. (2011). Seeley's Anatomy and Physiology: McGraw-Hill Companies.

Verellen, J., Meyer, C., Janssens, L., \& Vanlandewijck, Y. (2012). Peak and submaximal steady-state metabolic and cardiorespiratory responses during arm-powered and arm-trunk-powered handbike ergometry in able-bodied participants. Eur J Appl Physiol, 112(3), 983-989. doi: 10.1007/s00421-011-2051-8

Walter, J. S., Sacks, J., Othman, R., Rankin, A. Z., Nemchausky, B., Chintam, R., \& Wheeler, J. S. (2002). A database of self-reported secondary medical problems among VA spinal cord injury patients: its role in clinical care and management. $J$ Rehabil Res Dev, 39(1), 53-61.

Waring, W. P., 3rd, Biering-Sorensen, F., Burns, S., Donovan, W., Graves, D., Jha, A., . . . Stein, A. (2010). 2009 review and revisions of the international standards for the neurological classification of spinal cord injury. J Spinal Cord Med, 33(4), 346352.

West, C. R., Mills, P., \& Krassioukov, A. V. (2012). Influence of the neurological level of spinal cord injury on cardiovascular outcomes in humans: a meta-analysis. Spinal Cord, 50(7), 484-492. doi: 10.1038/sc.2012.17

Wilmore, Jack Harrison, Costill, David L., \& Kenney, W. Larry. (2008). Physiology of sport and exercise. Champaign, IL: Human Kinetics. 
Zurlo, F., Larson, K., Bogardus, C., \& Ravussin, E. (1990). Skeletal muscle metabolism is a major determinant of resting energy expenditure. J Clin Invest, 86(5), 14231427. doi: 10.1172/JCI114857 


\title{
CURRICULUM VITAE
}

\author{
John P. McCulloch \\ Permanent Address: 959 Baxter Ave Unit 105, Louisville, KY 40204 \\ Phone: 612-708-8639 \\ Email: john.mcculloch@louisville.edu
}

\section{Education}

Universty of Louisville, Louisville, KY

Degree: M.S. in Exercise Physiology

Graduation: August 2013

GPA: $3.757 / 4.0$

Thesis: VALIDATION OF AN RPE-BASED SUBMAXIMAL OXYGEN CONSUMPTION TEST USING A TOTAL BODY RECUMBENT STEPPER FOR INDIVIDUALS WITH SPINAL CORD INJURY: A PROOF OF CONCEPT STUDY

University of Dayton, Dayton, $\mathrm{OH}$

Degree: B.S. Education and Allied Professions

August 2007 - May 2011

GPA: $3.02 / 4.0$

Major: Pre-Physical Therapy

\section{Teaching Experience}

1. Department of Health and Sport Sciences, University of Louisville, Louisville, KY. Summer 2013: HSS 396 - Health/Fitness Instructor Lab (teaching assistant)

2. Department of Health and Sport Sciences, University of Louisville, Louisville, KY. Spring 2013: HSS 396 - Health/Fitness Instructor Lab (teaching assistant)

3. Department of Health and Sport Sciences, University of Louisville, Louisville, KY. Spring 2013: HSS 109 - Weight Training

4. Department of Health and Sport Sciences, University of Louisville, Louisville, KY. Fall 2012: EXP 601 - Lab Methods in Exercise Physiology (teaching assistant)

5. Department of Health and Sport Sciences, University of Louisville, Louisville, KY. Fall 2012: HSS 396 - Health/Fitness Instructor Lab (teaching assistant)

6. Department of Health and Sport Sciences, University of Louisville, Louisville, KY. Fall 2012: HSS 114 - Fitness Walking

7. Department of Health and Sport Sciences, University of Louisville, Louisville, KY. Fall 2012: HSS 109 - Weight Training

8. Department of Health and Sport Sciences, University of Louisville, Louisville, KY. Summer 2012: HSS 396 - Health/Fitness Instructor Lab (teaching assistant) 
9. Department of Health and Sport Sciences, University of Louisville, Louisville, KY. Summer 2012: HSS 110 - Physical Fitness and Conditioning

10. Department of Health and Sport Sciences, University of Louisville, Louisville, KY. Spring 2012: HSS 396 - Health/Fitness Instructor Lab (teaching assistant)

11. Department of Health and Sport Sciences, University of Louisville, Louisville, KY. Spring 2012: HSS 114 - Fitness Walking

12. Department of Health and Sport Sciences, University of Louisville, Louisville, KY. Spring 2012: HSS 109 - Weight Training

13. Department of Health and Sport Sciences, University of Louisville, Louisville, KY. Fall 2011: HSS 114 - Fitness Walking

14. Department of Health and Sport Sciences, University of Louisville, Louisville, KY. Fall 2011: HSS 110 - Physical Fitness and Conditioning

\section{Academic Appointments}

2011-Present Graduate Teaching Assistant, Department of Exercise Physiology, University of Louisville, Louisville, KY

2011 Student Assistant, Adapted Physical Education, Health and Sport Science, University of Dayton, Dayton, $\mathrm{OH}$

\section{Studies}

1. John McCulloch, B.S.; Ann Swank, Ph.D.; Sevda Aslan, Ph.D.; Saori HanakiMartin, Ph.D.; Douglas Lorenz, Ph.D.; Daniela Terson de Paleville, Ph.D. VALIDATION OF AN RPE-BASED SUBMAXIMAL OXYGEN CONSUMPTION TEST USING A TOTAL BODY RECUMBENT STEPPER FOR INDIVIDUALS WITH SPINAL CORD INJURY: A PROOF OF CONCEPT STUDY. 2013.

2. John McCulloch, B.S.; Daniel C. Funk, Ph.D.; John Manire, M.S.; Amy Allard, M.S.; D. Martin Denny, M.D.; Ann M. Swank, Ph.D. Effect of Resistance Training and Aerobic Conditioning on Muscular Strength and Submaximal Fitness for Individuals with Chronic Heart Failure: Influence of Type 2 Diabetes. 2012.

3. Colin Fitzsimmons, B.S.; John McCulloch, B.S.; Luke Wakefield, M.S.; Saori Hanaki-Martin, PhD. Effect of Topical Menthol on Aerobic Capacity. 2012.

\section{Conferences}

1. American Psychological Association National Conference, Orlando, FL, 2012. Effect of Resistance Training and Aerobic Conditioning on Muscular Strength and Submaximal Fitness for Individuals with Chronic Heart Failure: Influence of Type 2 Diabetes.

2. Research!Louisville, Louisville, KY, 2012. Effect of Resistance Training and Aerobic Conditioning on Muscular Strength and Submaximal Fitness for Individuals with Chronic Heart Failure: Influence of Type 2 Diabetes.

3. Experimental Biology, Boston, MA, 2013. Validation of submaximal oxygen consumption tests using an arm crank ergometer and NuStep ergometer for individuals with spinal cord injury. (Abstract submitted) 


\section{Certifications and Memberships}

- American Heart Association CPR (Expires May 2013)

- American Herat Association First Aid (Expires May 2013)

- Member of the National Strength and Conditioning Association (2010 - Present)

- Member of the American College of Sports Medicine (2012 - Present)

\section{Work Experience}

University of Louisville, Louisville, KY

August 2011-Present

Graduate Research and Teaching Assistant

- Teach health and fitness courses

- Assist in teaching undergraduate courses

- Run physical fitness assessment tests

- Assist with ongoing studies

University of Dayton Rec Plex, Dayton, $\mathrm{OH}$

January 2010-May 2011

Fitness Attendant

- Supervise facility

- Run fitness assessments

- Clean and fix equipment

- Act as first responder in case of emergency

\section{Other Experience}

Minnesota Sport and Spine Rehabilitation, Burnsville, MN

May 2009-August 2009

Student Intern

- Observed assessment and treatment of sport, work, and general injuries

Capernaum Pediatrics, New Hope, MN

June 2009-August 2009

Student Intern

- Observed treatment of children with various mental disabilities ranging from severe downs-syndrome to mild cerebral palsy

Methodist Hospital, St. Louis Park, MN

June 2002-May 2005

Volunteer

- Discharged patients, ran errands for doctors and nurses, delivered medications to nursing stations 


\section{Activities, Honors, and Awards}

- University of Louisville Graduate School Dean's Citation Award Winner 2013

- University of Louisville Exercise Physiology Outstanding Student Award 2013

- University of Louisville Health and Human Performance Club

- Club Founder: formed January 2012

o President: January 2012 - Present

- President's Scholarship at the University of Dayton for holding GPA over 3.0

- Pre-Physical Therapy Club: September 2008-2011

- University of Dayton Men's Crew team 2007- 2010

- Fundraising Chair: November 2008-December 2009

○ Treasurer: January 2009-June 2009

- Eagle Scout awarded December 2006 